\title{
THE GREAT COLORADO FLOOD OF SEPTEMBER 2013
}

by David Gochis, Russ Schumacher, Katja Friedrich, Nolan Doesken, Matt Kelsch, Juanzhen Sun, Kyoko Ikeda, Daniel Lindsey, Andy Wood, Brenda Dolan, Sergey Matrosov, Andrew Newman, Kelly Mahoney, Steven Rutledge, Richard Johnson, Paul Kucera, Pat Kennedy, Daniel Sempere-Torres, Matthias Steiner, Rita Roberts, Jim Wilson, Wel Yu, V. Chandrasekar, Roy Rasmussen, Amanda Anderson, and Barbara Brown

A detailed overview of the uncharacteristic meteorological conditions that caused tropicallike, widespread, heavy rainfall and catastrophic flooding across the Colorado Front Range in September 2013 .

D uring the period of 9-16 September 2013, a large area of heavy rainfall, with local amounts exceeding $450 \mathrm{~mm}$, fell over a broad region of the Colorado Front Range foothills and adjacent plains (Figs. 1, 2). An event timeline shown in Fig. 3

AfFiliations: Gochis, Kelsch, Sun, IKedA, WoOd, NeWman, Kucera, Steiner, Roberts, Wilson, Yu, Rasmussen, Anderson, and BroWnNational Center for Atmospheric Research, Boulder, Colorado; Schumacher, Doesken, Dolan, Rutledge, Johnson, Kennedy, and ChANDRASEKAR - Colorado State University, Fort Collins, Colorado; FRIEDRICH AND MAHONEY - University of Colorado Boulder, Boulder, Colorado; LINDSEY - NOAA/Center for Satellite Applications and Research, College Park, Maryland; MATROsov-University of Colorado Boulder, and National Oceanic and Atmospheric Administration/Earth Systems Research Laboratory, Boulder, Colorado; Sempere-Torres-Centre de Recerca Aplicada en Hidrometeorologia, Universitat Politecnica de Catalunya, Barcelona, Spain CORRESPONDING AUTHOR: David J. Gochis, NCAR/UCAR, 3090 Center Green Drive, Boulder, CO 8030I

E-mail: gochis@ucar.edu

The abstract for this article can be found in this issue, following the table of contents.

DOI:10.1175/BAMS-D-13-0024I.I

In final form 4 November 2014

(C)2015 American Meteorological Society chronicles the sequence of events both leading up to and following the core periods of heavy rainfall and flooding. The most intense, widespread, and persistent rainfall along the Front Range occurred on 11-12 September. While flash flooding from locally heavy rainfall in mountain canyons is not uncommon in this region, many characteristics of the September 2013 floods were exceptional. These characteristics include the protracted duration of heavy rainfall and the widespread spatial extent and prolonged duration of flooding days to weeks following the cessation of rainfall. Not only were flooding impacts felt in narrow mountain canyons, but flooding across the Front Range combined into a large-scale, multistate flood event as tributary waters swelled and flowed down the South Platte River onto the high plains across northeast Colorado and into Nebraska.

The severe flooding of many regional river systems, localized flash flooding, and the landslides and debris flows that occurred claimed eight lives and produced damage, exceeding $\$ 2$ billion (U.S. dollars) (A. Smith, National Climatic Data Center, 2014, personal communication; NWS 2014), to private and public properties in Front Range communities. Federal, state, and local emergency response entities including multiple U.S. National Guard units were activated 


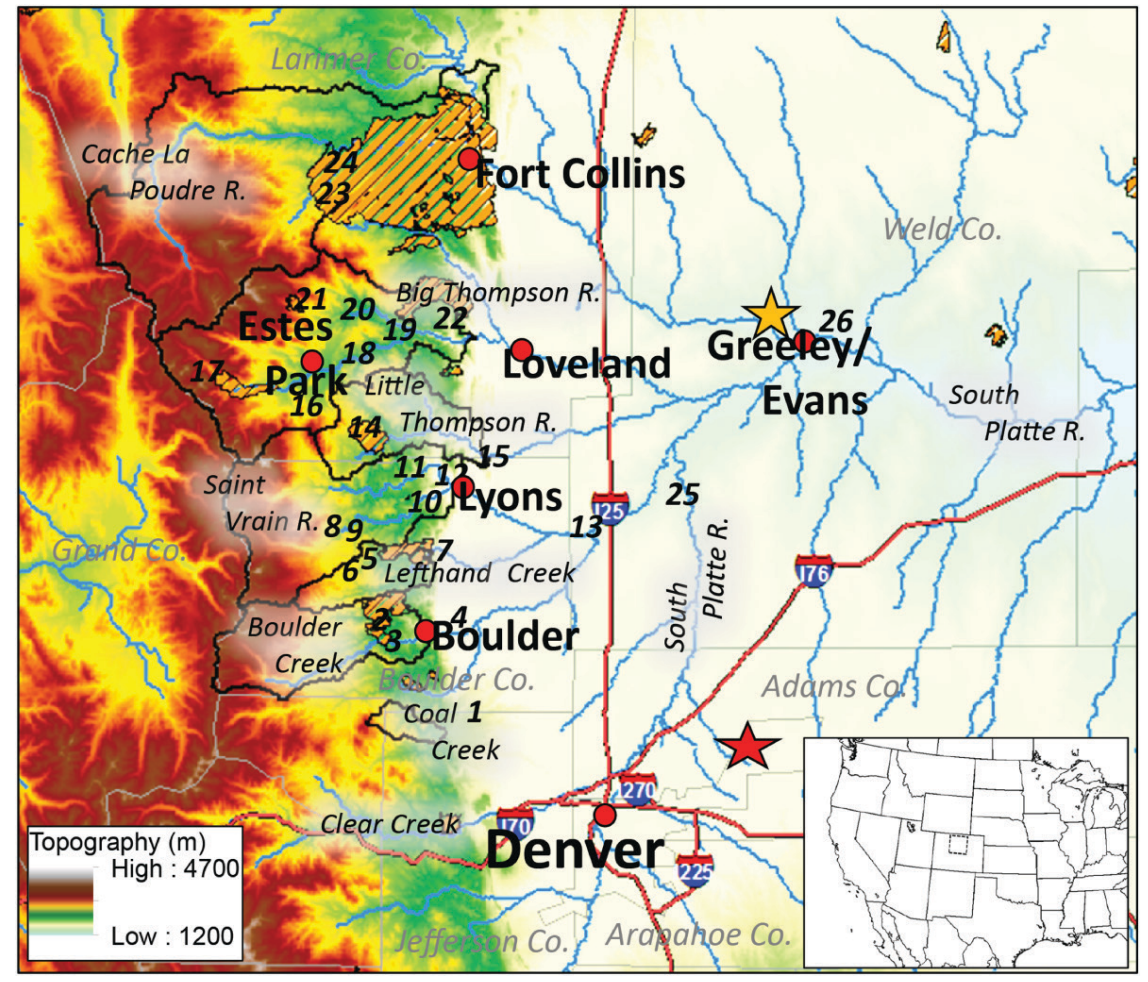

FIG. I. Regional map of the Colorado Front Range. City names are in bold and indicated by red circles, river names are in black italics, and county names are in gray italics. Red star is the location of the Denver NEXRAD radar (KFTG), and the orange star denotes the location of the CSU-CHILL radar. Numbers on the map correspond to peak flow measurement locations listed in Table I. Some numbers lie on smaller streams not resolved in the map. USGS-defined wildfire perimeters are shown in orange hatching. and associated hydrologic responses. We explore the event in terms of largescale moisture transport patterns, the mesoscale features that localized heavy rainfall, and the storm- and cloud-scale processes that were observed by a comparatively rich and technologically advanced observational network, though many of those observations were not available in real time. In addition, this article recounts the event in the context of operational quantitative precipitation estimation (QPE), quantitative precipitation forecasts (QPFs), and operational flood forecasts. While the system that produced heavy rainfall occurred over a one-week period (916 September) and covered a large, multistate area, this article primarily focuses on the period of 11-13 September in Boulder and Larimer Counties of Colorado's to assist in rescue operations. Multiple communities in the region experienced massive destruction, and recovery efforts continue as of this writing. The level of destruction caused by the September floods of 2013 had not been witnessed in this region for several decades. Compiling information from the Colorado Climate Center, National Weather Service, and U.S. Geological Survey (USGS), as well as state and federal disaster response agencies, some of the major societal impacts are listed in the sidebar "Societal impacts from September 2013 Colorado floods" and many of the documented rainfall records that were set are detailed in the "Record rainfall" sidebar. As with any large natural disaster, these statistics form only a thin wrapper on the physical and emotional costs incurred to individuals and communities that have had to live through such events.

This study documents the climatological, meteorological, and surface hydrological processes responsible for producing such widespread destruction. The multiday event is examined from the perspective of the causative mechanisms for heavy rainfall northern Front Range, arguably the area most severely impacted by the September floods. It is important to note that several other areas of intense rainfall and flooding took place simultaneously in regions east and south of the northern Colorado Front Range, and also in parts of New Mexico and southern Wyoming. A complete description including these other areas is beyond the scope of this study.

The hydrometeorological processes described herein are organized according to space and time scales over which those processes operated, ranging from the large-continental, synoptic-climatic setting down to the scale of small watersheds. The "large scale" circulation setting (i.e., thousands of kilometers) in the period leading up to and during the flood event is described along with a chronology of heavy precipitation episodes along with a more "regional," or mesoscale (i.e., tens to hundreds of kilometers), description of atmospheric features that played important roles in localizing the regional rainfall patterns and contributed to episodes of particularly intense rainfall. Findings from a focused analysis 
of "cloud scale" processes of several different cloud and precipitation observational platforms that were operating during the event are then given. A chronology of the flooding generated by the heavy rainfall follows along with a summary discussion of runoff generation processes that played significant roles in translating rainfall into streamflow. A brief analysis of several of the operational QPEs is then provided followed by a short summary of several QPF products and National Weather Service (NWS) operational streamflow predictions. We conclude with a summary of lessons learned from this event so far and enumerate some of the opportunities for incorporating these findings into future hydrometeorological prediction systems. Last, while there is much to be learned from the shared experiences of people and institutions in coping with such natural disasters, this is outside the scope of this work. Therefore, we only attempt to provide a high-level, comprehensive overview of the hydrometeorological processes occurring during the September 2013 flooding event.

THE SYNOPTIC SETTING. The large-scale atmospheric pattern that supported persistent heavy rainfall in northern Colorado during 10-16 September 2013 consisted of a blocking ridge over the Canadian Rockies and a slow-moving, cutoff, upperlevel cyclonic circulation to its south over the western

\section{SOCIETAL IMPACTS FROM SEPTEMBER 2013 COLORADO FLOODS}

The September 2013 floods have left deep scars on the communities that lived through them. The final cost of the damage is still being tabulated but will likely exceed $\$ 2$ billion. Table SBI in this sidebar provides a basic summary of what these impacts were in terms of lives lost, communities disrupted, and transportation corridors destroyed. Figure SB Ia illustrates the widespread nature of the I,I38 documented debris flows that occurred during this event (Coe et al. 20I4) and Fig. SBIb shows the 18 counties that were declared by Federal Emergency Management Agency (FEMA) as federal disaster areas.

\section{TABLE SBI. List of impacts from the Great Colorado Floods of 2013.}

I. There were 8 flood-related fatalities (NWS 2014).

2. Emergency evacuation and civil protection operations were activated on 12 Sep 2013.

3. U.S. National Guard members in Colorado and Wyoming in coordination with the Department of Defense personnel from Fort Carson (4th Infantry) and Buckley Air Force Base evacuated more than 3,700 people from flooded communities.

4. Over 18,000 people were forced to leave their homes because of the flooding (FEMA).

5. Over I, I00 landslide and hillslope failures occurred during the event, which have been implicated in 3 of the 10 fatalities (Coe et al. 2014; Fig. SBIa).

6. Flooding destroyed at least I,882 structures (FEMA).

7. \$9 million of FEMA money was used for basic first responder activities (FEMA).

8. An official federal disaster was declared 14 Sep 2013 (FEMA).

9. 18 counties were designated for public assistance-Adams, Arapahoe, Boulder, Clear Creek, Crowley, Denver, El Paso, Fremont, Gilpin, Jefferson, Lake, Larimer, Lincoln, Logan, Morgan, Sedgwick, Washington, and Weld (Fig. SBIb) (FEMA).

10. More than 28,000 people registered for state and federal assistance, and more than 21,000 people visited disaster recovery centers.

I I. The National Flood Insurance Program approved more than $\$ 55.7$ million in claims.

12. As of 20 Dec 2013 , FEMA has distributed $\$ 204$ million to individuals and households and $\$ 28$ million to repair infrastructure.

13. Over $\$ 90$ million in Small Business Administration loans have been given to businesses and nonprofits and local governments.

14. Statewide, 485 miles of damaged or destroyed highways [Colorado Department of Transportation (CDOT) news release].

15. Of the 18 counties designated for assistance, Boulder County was hardest hit in terms of damages receiving more than $\$ 33$ million in state and federal reconstruction grants (FEMA) and over 150 miles of road were destroyed in Boulder County alone (28 Sep, Daily Camera). 


\section{SOCIETAL IMPACTS FROM SEPTEMBER 2013 COLORADO FLOODS, CONTINUED}
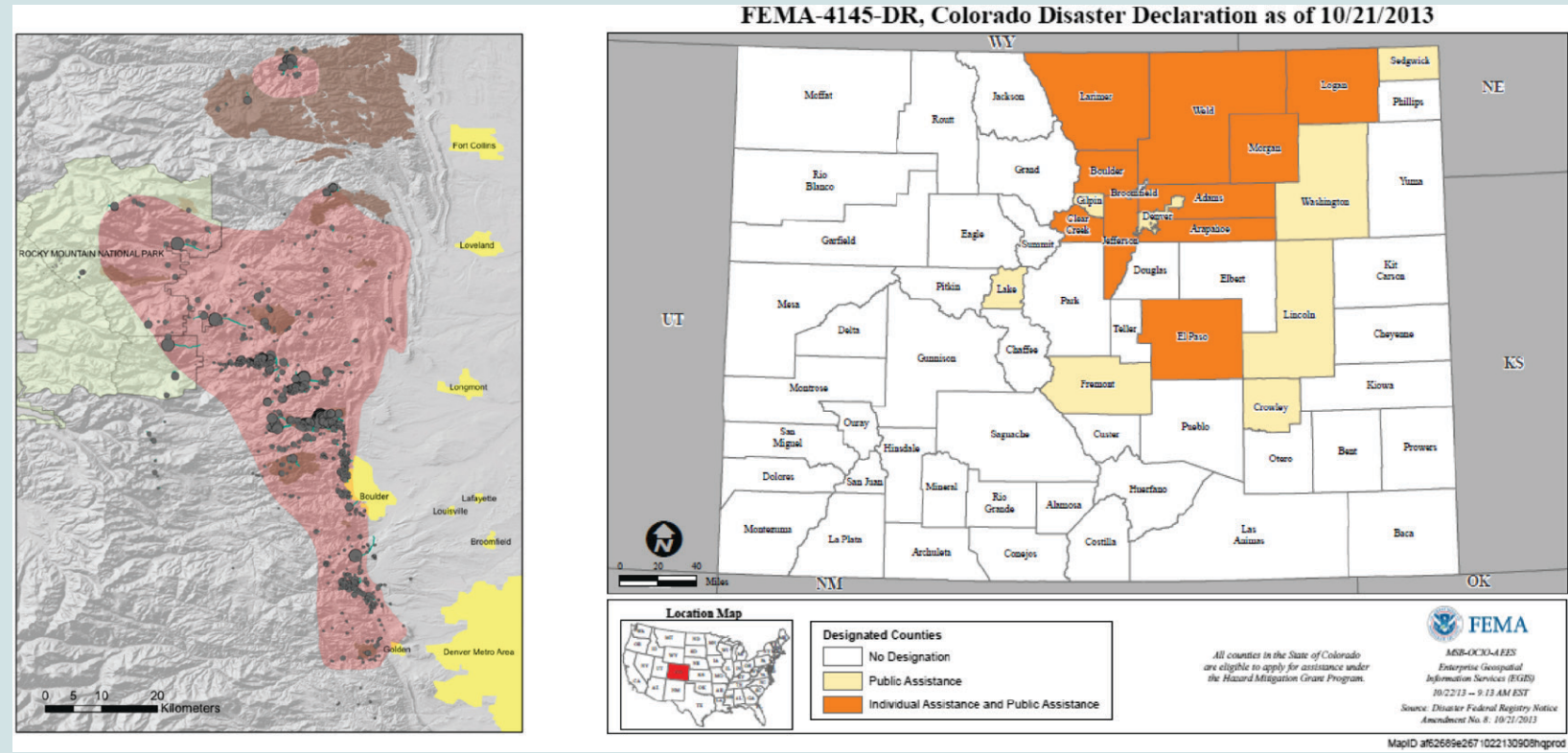

FIG. SBI. (a) Map of over I, 100 documented hillslope failures prepared by Jonathan Godt and Geff Coe of USGS. Green dots are location and proportional size of hillslope failures, yellow shading denotes city areas, red shading outlines the region of heavy rainfall, and brown shading outlines regions of recent wildland fires. (b) FEMA map of Colorado disaster county declarations.

United States (Figs. 4a,b). The blocking anticyclone assisted in keeping the western U.S. cutoff circulation in place for several days, and to the east and southeast of this circulation, moist air was transported northward and westward toward the Front Range in Colorado (Figs. 4b-d). The 500-hPa pattern bears some similarity to the Maddox (1980) type I western flash flood pattern (their Fig. 1), with a strong ridge over western North America, although Maddox's (1980) pattern showed the heavy rainfall occurring near a short-wave trough moving northward on the west side of the ridge rather than ahead of a cutoff circulation underneath the ridge.

The week preceding the flood event (2-8 September) was marked by a stretch of extreme heat in the Colorado Front Range region where three daily high temperature records were tied or broken in Denver (NWS 2013b). This heat wave was associated with a large blocking ridge across western North America (Fig. 4a). Northward flow along the western periphery of the North American subtropical anticyclone, situated over the southeast United States (Fig. 4a), intensified on 10-11 September and, in concert with the stagnating cutoff low to the west, began to support deep southerly flow into the high plains, as well as easterly (upslope) low-level flow into the Colorado Front Range (Fig. 4d). Furthermore, a long eastwest surface baroclinic zone extended from eastern Canada westward into Colorado (see broad swath of east-west-oriented clouds in Fig. 4b) with an associated surface front served, in addition to orographic lift, as a persistent low-level focusing mechanism for ascent along the Front Range during 11-13 September.

This large-scale atmospheric flow pattern brought highly anomalous moisture to northern Colorado for an extended period of time during 9-16 September (Fig. 4c). The moisture source for this transport appears to have been fed by broader-scale anomalous oceanic conditions in the Western Hemisphere tropical oceans where positive sea surface temperature (SST) anomalies from $1^{\circ}$ to $3^{\circ} \mathrm{C}$ were observed (Fig. A1). Standardized anomalies (e.g., Hart and Grumm 2001) of precipitable water (PW) were two to four standard deviations above normal in a corridor extending from the Gulf of Mexico and the tropical eastern Pacific into the Intermountain West near and ahead of the cutoff circulation (Fig. 4c). The Denver radiosonde observation set new daily records for $\mathrm{PW}$ 


\section{RECORD RAINFALL}

Ceveral precipitation records were broken during the September 2013 event. A USGS rain gauge at Fort Carson, near Colorado Springs (south of the map shown in Fig. I), accumulated $301 \mathrm{~mm}$ (II.85 in.) of rain from midnight to midnight local time of 12-13 September and 316 mm (12.46 in.) from 0900 LT 12 September to 0900 LT 13 September. This accumulation established a new daily rainfall extreme for the entire state of Colorado surpassing the long-standing gauge measurement of 28I.4 mm (II.08 in.) on 17 June 1965. The city of Boulder set several local station records for I-day (230.6 mm or $9.08 \mathrm{in}$.), 2-day (292.6 $\mathrm{mm}$ or II.52 in.), 3-day (34I.8 or I3.44 in.), 7-day (429.3 mm or $16.9 \mathrm{in}$.), and monthly (461.2 $\mathrm{mm}$ of $18.16 \mathrm{in}$.) rainfall records. The city of Denver also set a precipitation accumulation record for the month of September
(142.5 mm or 5.61 in.; NWS 2013b). Three of the top 10 largest I-day rain events in state history will now be associated with the September 2013 storm. Additionally, according to analyses performed by the NOAA/Hydrometeorological Design Center, the annual exceedance probability for the worst-case $24-\mathrm{h}$ precipitation was estimated to be less than I/I,000 (NWS 20I3a; Fig. SB2). This has led some to erroneously label the resulting flood as a "I,000-yr flood" event. However, return periods of rainfall events often do not directly relate to the return period of the resulting flood. Nevertheless, the heavy rainfall in the foothills and mountains resulted in over 1,100 documented landslides (see the sidebar on the "Societal impacts from September 2013 Colorado floods"; Coe et al. 2014) and led to the incredible flood damage described below.

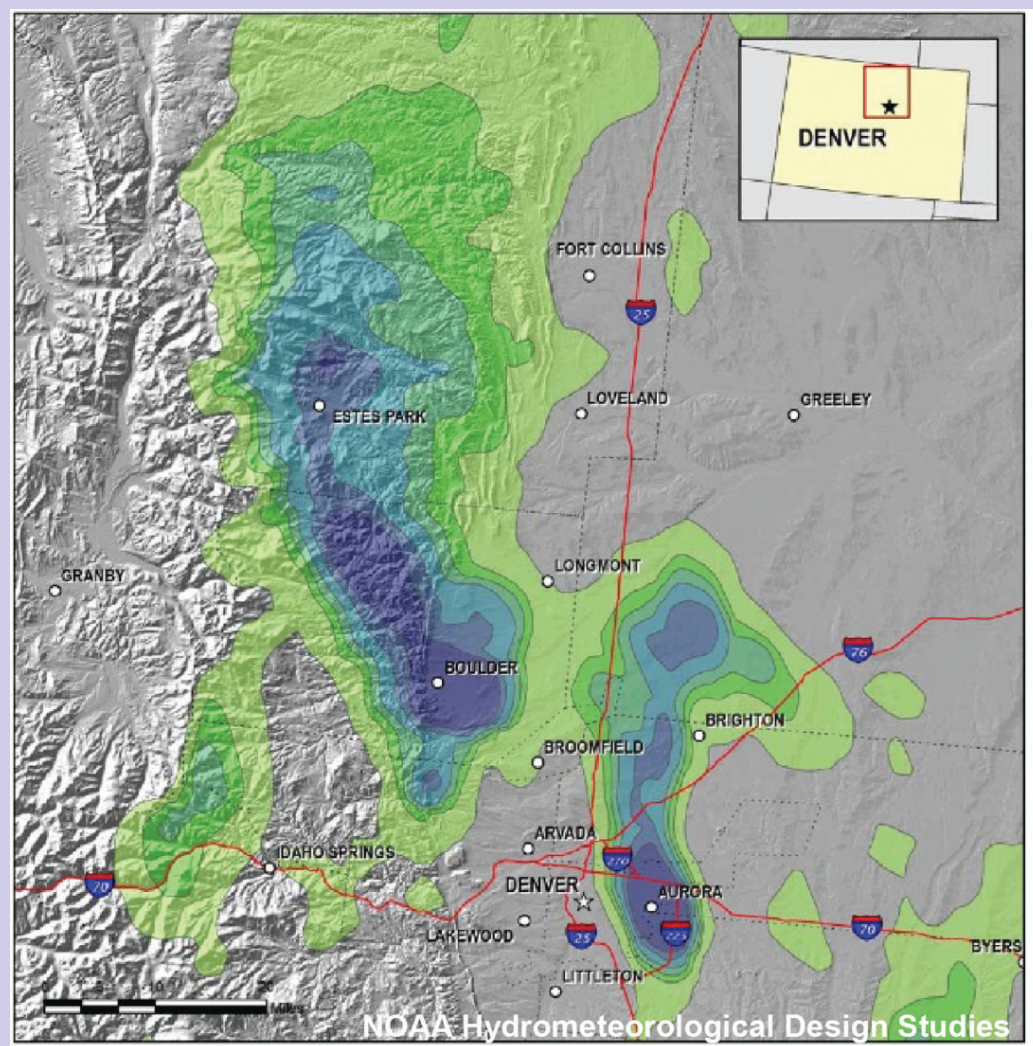

Probability of exceedance (= 1 / years)

$>1 / 10$

$1 / 50-1 / 10$

$1 / 100-1 / 50$

$1 / 200-1 / 100$

$1 / 500-1 / 200$

$1 / 1000-1 / 500$

$<<1 / 1000$

Colorado Flood Event, 9-16 Septemner 2013

Annual Exceedance Probabilities (AEPs) for Worst Case 24-hour Rainfall

FIG. SB2. The 9-16 Sep annual exceedance probabilities for worst-case 24-h rainfall (NWS 2013a).

for six consecutive 12-hourly soundings (Fig. 5a), with PW exceeding $25 \mathrm{~mm}$ in nearly all soundings during 10-16 September, a high value for this climatologically dry region and season. On 12 September, the easterly winds at $700 \mathrm{hPa}$ (Figs. 5b, 4d) were greater than three standard deviations away from the mean in northern Colorado with anomalous easterlies in place from 8 to 16 September.

The atmospheric sounding from Denver in Fig. 5b indicates that lower-atmospheric stability during this 


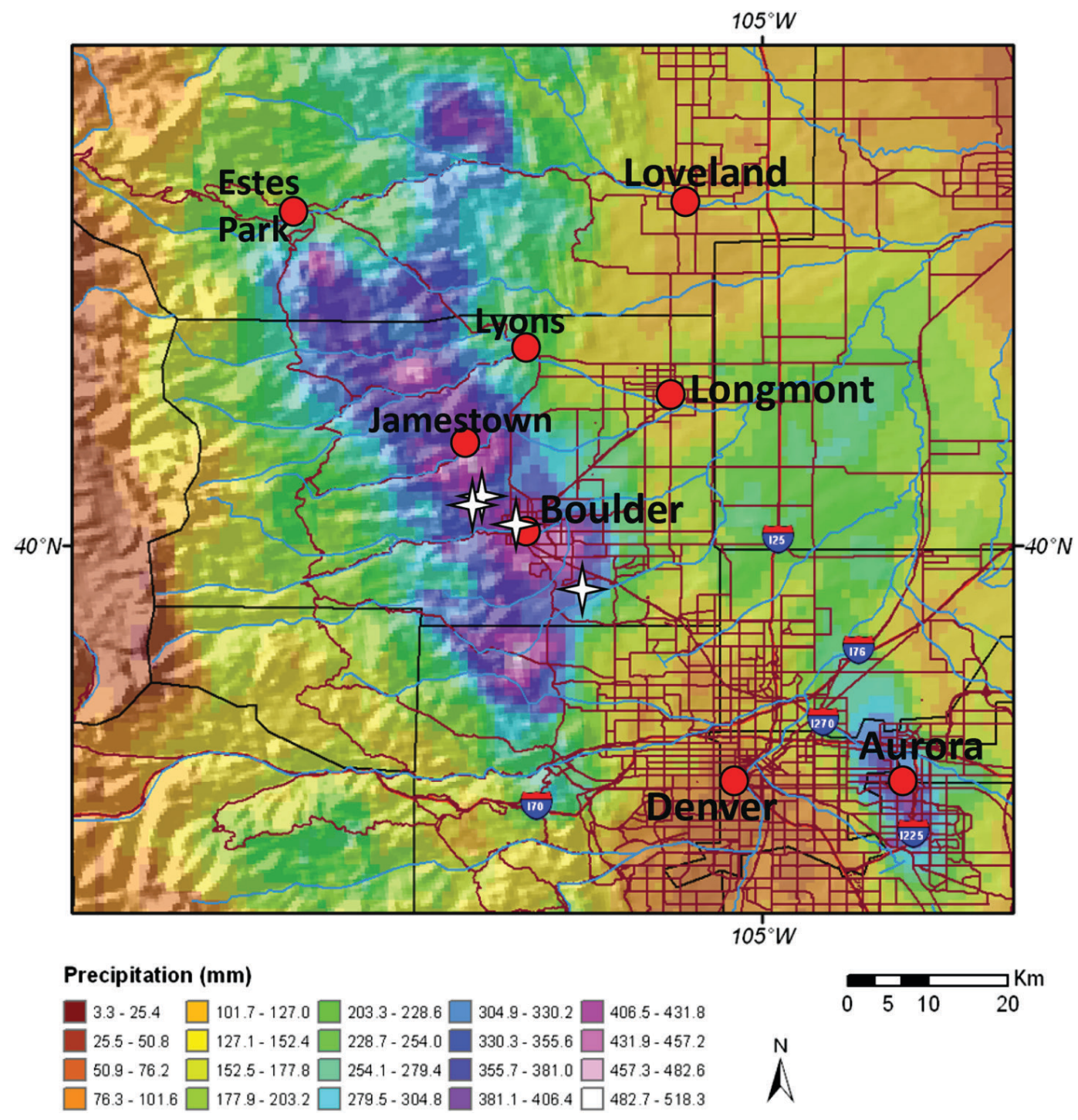

FIG. 2. The 9-17 Sep 2013 total accumulated precipitation $(\mathrm{mm})$ created with the Storm Precipitation Analysis System through a collaborative effort by Applied Weather Associates, LLC; MetStat, Inc.; and the Colorado Climate Center (Colorado State University). Dark red lines denote major roads and highways. Red dots approximate town and city center locations. White stars indicate locations of research laser disdrometers.

period of near-saturated conditions was largely moist adiabatic and neutral with only modest amounts of convective available potential energy (CAPE) present (see indices in Fig. 5b). Although this sounding passed through cloud and precipitation on ascent and thus is not representative of cloud-free conditions, it is generally similar in structure to other Denver soundings during this week. Furthermore, the presence of only modest CAPE is consistent with the Storm Prediction Center's real-time mesoanalysis over much of eastern Colorado (not shown). Comparing this sounding to the mean 1200 UTC September temperature and dewpoint soundings reveals that the dewpoint is considerably greater than one standard deviation above the September mean from the surface to $400 \mathrm{hPa}$. There was a very high freezing level (approximately $600 \mathrm{hPa}$ or $4,200 \mathrm{~m}$ ), such that precipitation took the form of rain all the way to the highest levels of the terrain. Finally, there was a prominent isothermal layer at $0^{\circ} \mathrm{C}$, indicating an important role of ice processes in precipitation formation, although considerable warm rain below this level likely also occurred.

\section{THE EVOLUTION OF RAINFALL BETWEEN} I I AND I5 SEPTEMBER 20 I3. As tropical moisture moved into the region on 10-11 September, temperatures remained in the $16^{\circ}-18^{\circ} \mathrm{C}$ range (low $60 \mathrm{~s}^{\circ} \mathrm{F}$ ) and widely scattered storms ensued. Repeated periods 

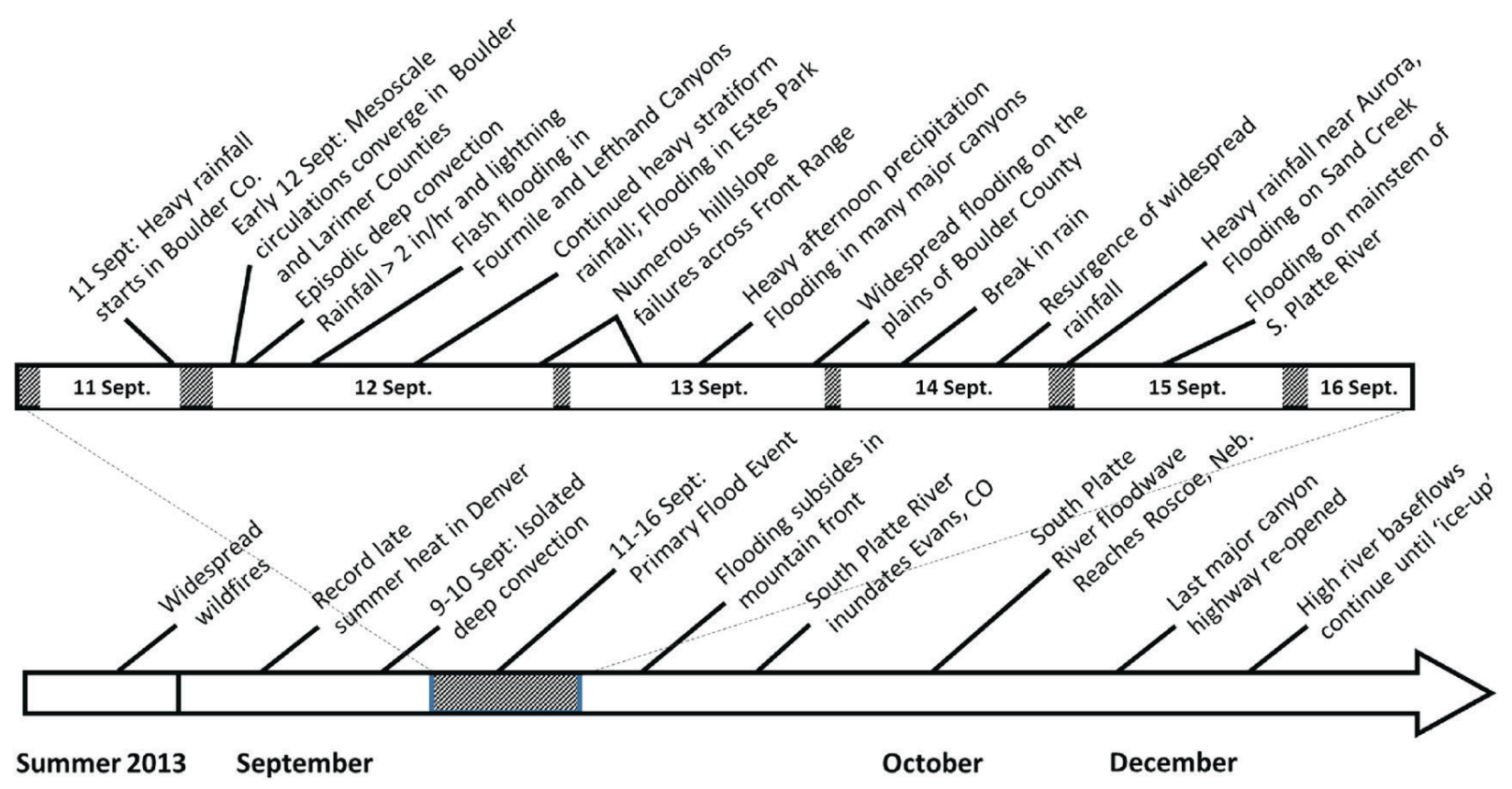

Fig. 3. Timeline of Sep 2013 hydrometeorological event.

of heavy rainfall (i.e., rain rates around $25 \mathrm{~mm} \mathrm{~h}^{-1}$ or greater) and flooding began in the evening (local time) on 11 September with the heaviest rains focusing on the Front Range (see Fig. 1 for a map of the local geography). Local, sustained rates between 25 and 50 $\mathrm{mm} \mathrm{h}^{-1}\left(1-2 \mathrm{in} . \mathrm{h}^{-1}\right)$ occurred near Boulder spreading northwest into the mountains toward Estes Park, Colorado. Heavy rainfall in and along the mountain front accumulated overnight, resulting in total amounts exceeding $200 \mathrm{~mm}$ (8 in.) in many locations and amounts over $50 \mathrm{~mm}$ ( $2 \mathrm{in}$.) extending all the way up to the Continental Divide. Persistent rainfall continued through 12 September becoming intense again in the afternoon, increasing rainfall totals in the heaviest hit areas to over $380 \mathrm{~mm}$ (15 in.).

Heavy rains diminished to widespread drizzle and intermittent showers during the day on 13 September. Clearing weather on 14 September allowed air support and emergency rescue efforts for approximately 24 hours (see timeline in Fig. 3 and list of event impacts in the sidebar on "Record rainfall"). Heavy rains, some associated with deep convection, returned on Saturday afternoon (14 September), primarily on the plains east of Interstate 25 with flooding occurring northeast of the cities of Denver and Aurora. One last surge of moisture with widespread 25-50-mm (1-2 in.) rains occurred across the entire Front Range during the day on 15 September. Rainfall rates during this final episode were moderate but widespread and occurred on saturated soils so that runoff production was very high.
Figure 6 shows a time-longitude evolution of the rainfall event as depicted by radar reflectivity from the Denver (KFTG) Weather Surveillance Radar-1988 Doppler (WSR-88D) from 9 to $13 \mathrm{Sep}$ tember. Two distinct rainfall regimes are observed: one in which radar echoes show a west-to-east (lowerleft to upper-right track) movement (0000 UTC 9 September-0000 UTC 11 September) and a second regime where radar echoes are either stationary or have an east-to-west (lower-right to upper-left track) or "upslope" movement (0000 UTC 11 September-0000 UTC 13 September). Figure 6b highlights this second quasi-stationary and upslope regime and reveals the presence of persistent, stationary, and/ or regenerating radar echoes over the mountains for nearly 48 hours (the region within the dotted inset box in Fig. 6b). These radar echoes approach $40 \mathrm{dBZ}$ just after 0000 UTC 12 September and again around 0000 UTC 13 September. Farther east, many echoes during this period are seen moving toward the mountains. This period of persistent heavy rainfall along the mountains within the dotted box was the predominant source of rain associated with most of the catastrophic flooding that occurred in Boulder and Larimer Counties.

The spatial pattern of the storm total rainfall shown in Fig. 2 reveals a complex structure. Although orographic lifting was a key process contributing to heavy rainfall, the southeast-to-northwest swath of heaviest rainfall (see Fig. 2) was not directly aligned with the regional north-south orographic slope. The mesoscale 


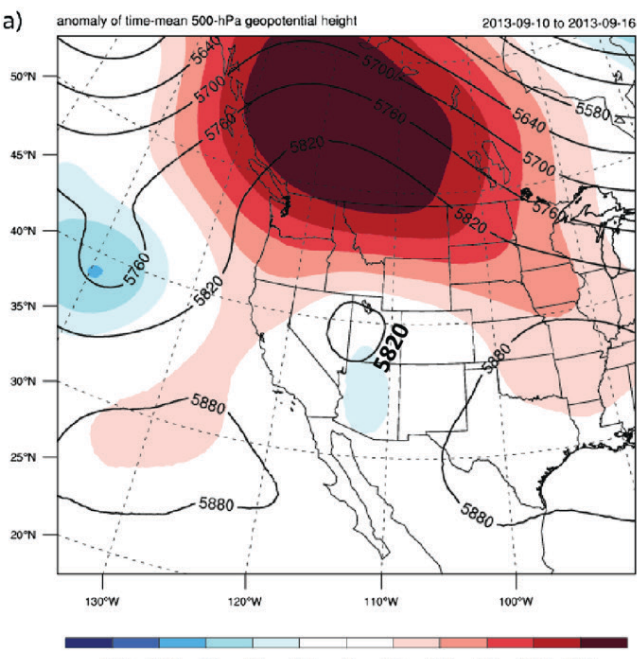

$\begin{array}{lllllllllll}-125 & -100 & -75 & -50 & -25 & 0 & 25 & 50 & 75 & 100 & 125\end{array}$

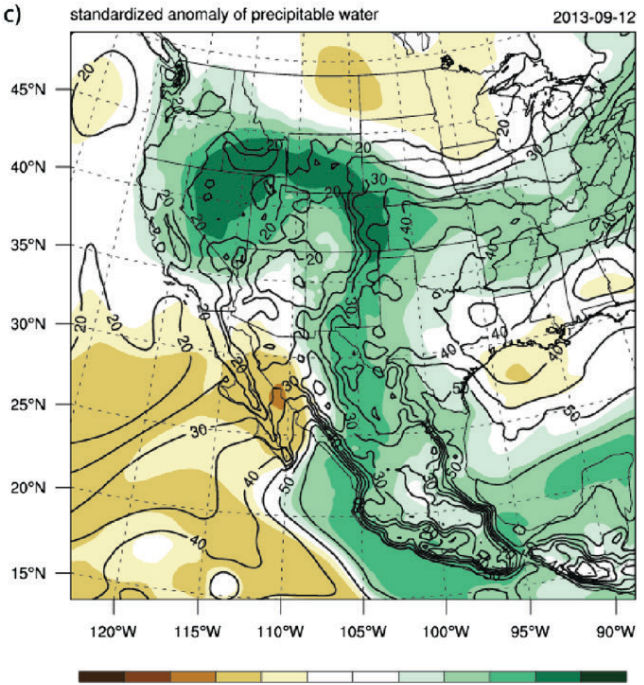

$\begin{array}{lllllllllll}-4 & -3 & -2 & -1 & -0.5 & 0 & 0.5 & 1 & 2 & 3 & 4\end{array}$
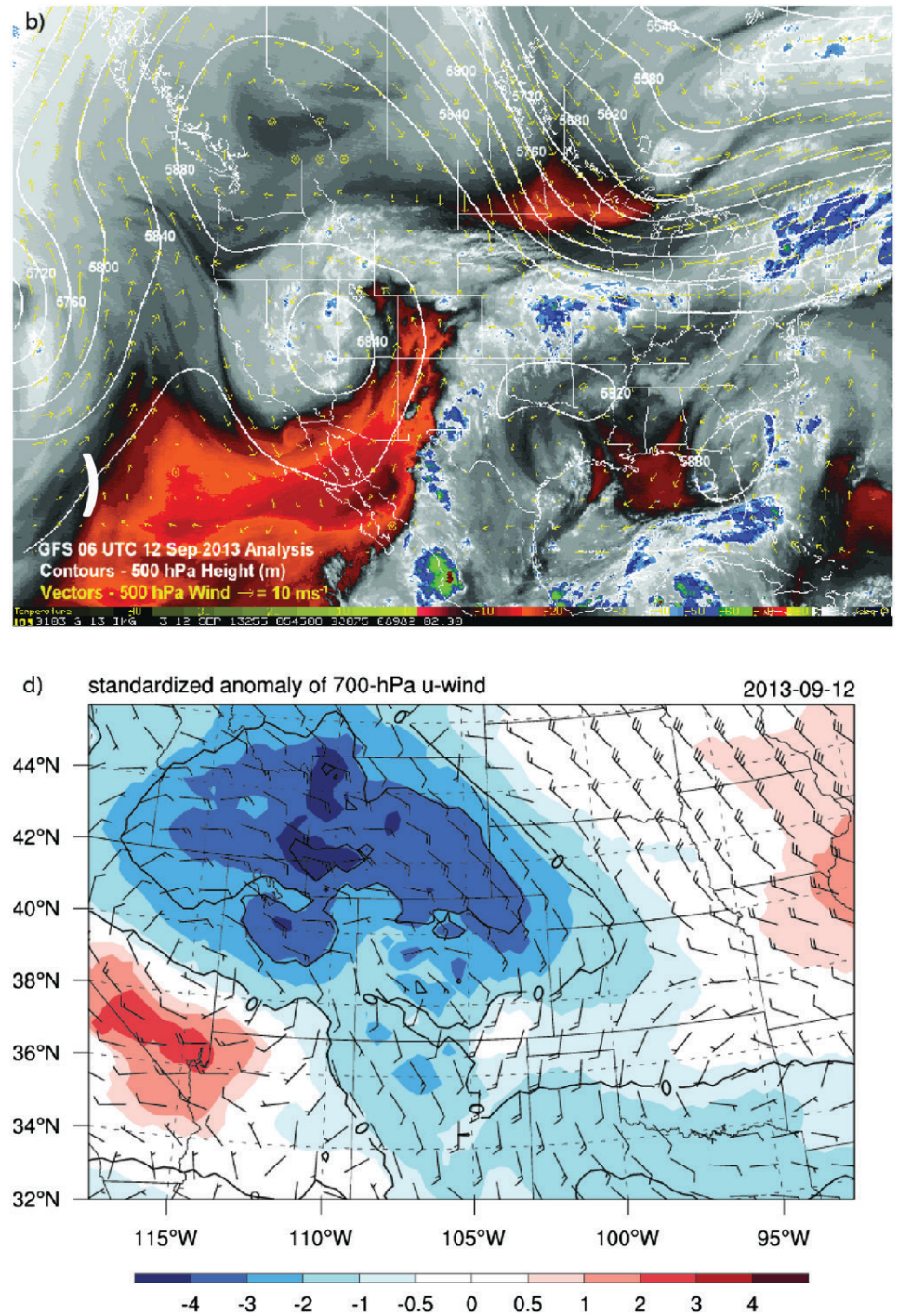

Fig. 4. (a) Time-mean 500-hPa geopotential height (black contours every $60 \mathrm{~m}$ ) and anomaly (color shading in $\mathrm{m})$; (b) GOES-13 water vapor image, $500-\mathrm{hPa}$ geopotential height $(\mathrm{m})$, and $500-\mathrm{hPa}$ wind vectors at 0600 UTC 12 Sep 2013; (c) column-integrated precipitable water (black contours every $5 \mathrm{~mm}$ ) and standardized anomaly (color shading in units of standard deviations) for I 2 Sep 20 I3; and (d) 700-hPa zonal wind (black contours every $5 \mathrm{~m} \mathrm{~s}^{-1}$ for values $\leq 0$ ), wind barbs, and standardized anomalies (color shading). Atmospheric fields come from the North American Regional Reanalysis (NARR; Mesinger et al. 2006), and standardized anomalies were calculated using the method of Hart and Grumm (200I) with a 2I-day window.

circulation features contributing to this complex evolution and pattern of rainfall are discussed in the following section. The most extreme rainfall amounts (totals in excess of $400 \mathrm{~mm} ; 16 \mathrm{in}$.) were measured within the city limits of Boulder and in the foothills to the west and northwest. The area of heaviest rainfall extended northwestward into the St. Vrain, Little Thompson, and the southern half of the Big Thompson watersheds. Rainfall in excess of $250 \mathrm{~mm}$ (10 in.) for the week was measured at elevations as high as 3,300 $\mathrm{m}(10,000 \mathrm{ft})$ and as far west as Estes Park. A more detailed description of the precipitation records set during the September flood event is provided in the sidebar on "Record rainfall."

\section{MESOSCALE CIRCULATION FEATURES.}

While synoptic-scale features conditioned the environment for a persistent wet period over a broad region from southern Wyoming through central New Mexico, there were many mesoscale processes responsible for localizing heavy rainfall along the mountain front regions of Colorado and for the episodes of especially heavy rainfall that exacerbated flooding responses in Boulder and Larimer Coun- 

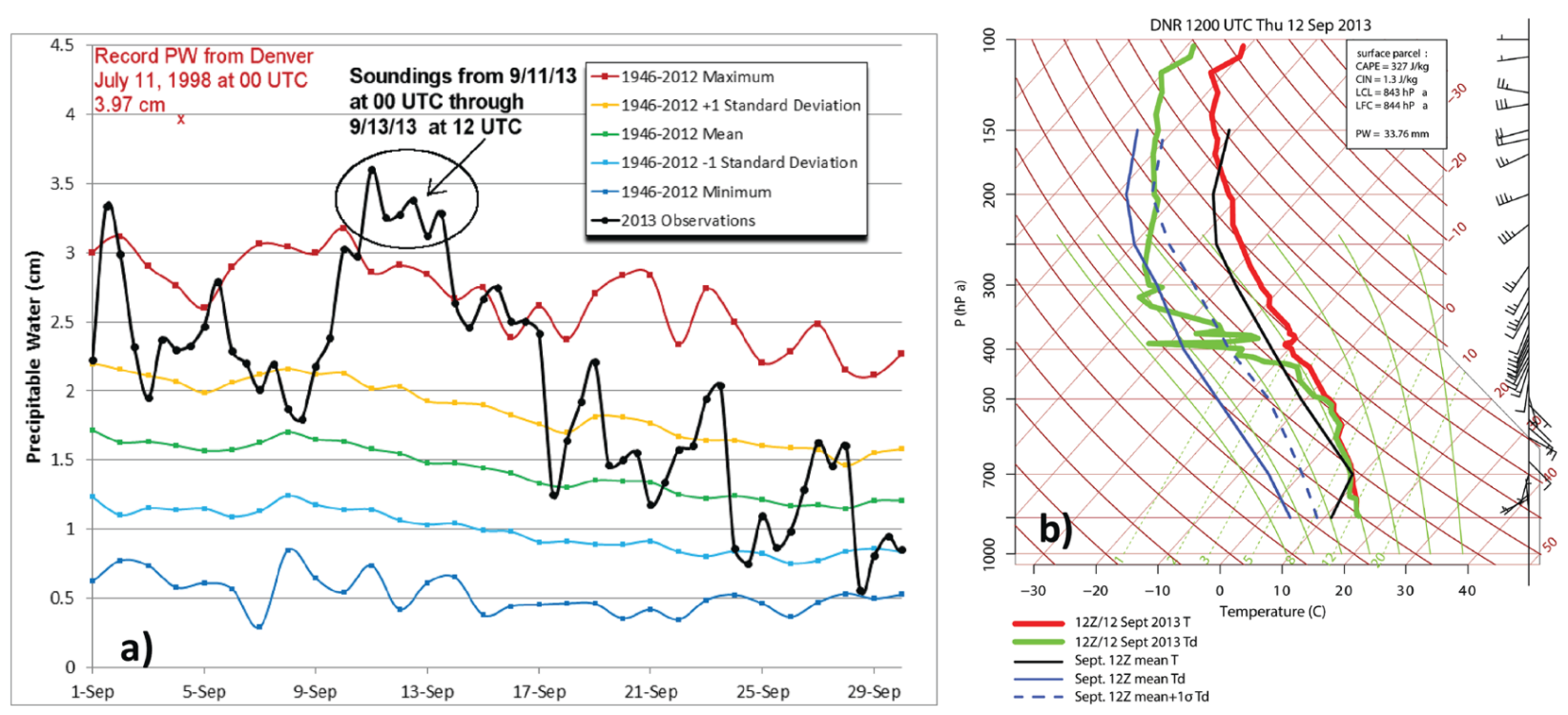

Fig. 5. (a) PW (in cm) from the surface to $300 \mathrm{hPa}$ as measured from radiosondes in Denver. Plotted are the daily means, maxima, minima, and one standard deviation above and below the means for days in Sep based on climatological data from 1946 to 2012 for Sep. Also plotted are the values measured in Sep 2013 (in black). Six consecutive soundings from 0000 UTC II Sep to I200 UTC I3 Sep set new single-day PW records. The all-time Denver PW record from II Jul 1998 is also plotted for reference. (b) Skew T-logp diagram of the sounding from Denver at I200 UTC I2 Sep 2013. The solid red line shows temperature, and the solid green line shows dewpoint at this time. The solid black line shows the mean I200 UTC temperature for Sep, the solid blue line shows the mean I200 UTC Sep dewpoint, and the dashed blue line shows the mean dewpoint plus one standard deviation. These mean and standard deviation calculations used observations from 1957 to 2012 and only mandatory levels. The 1200 UTC 12 Sep 2013 sounding was launched into cloud and precipitation, which is representative of the widespread moist upslope conditions in Colorado during II-13 Sep but may not be representative of the conditions in cloud-free areas.

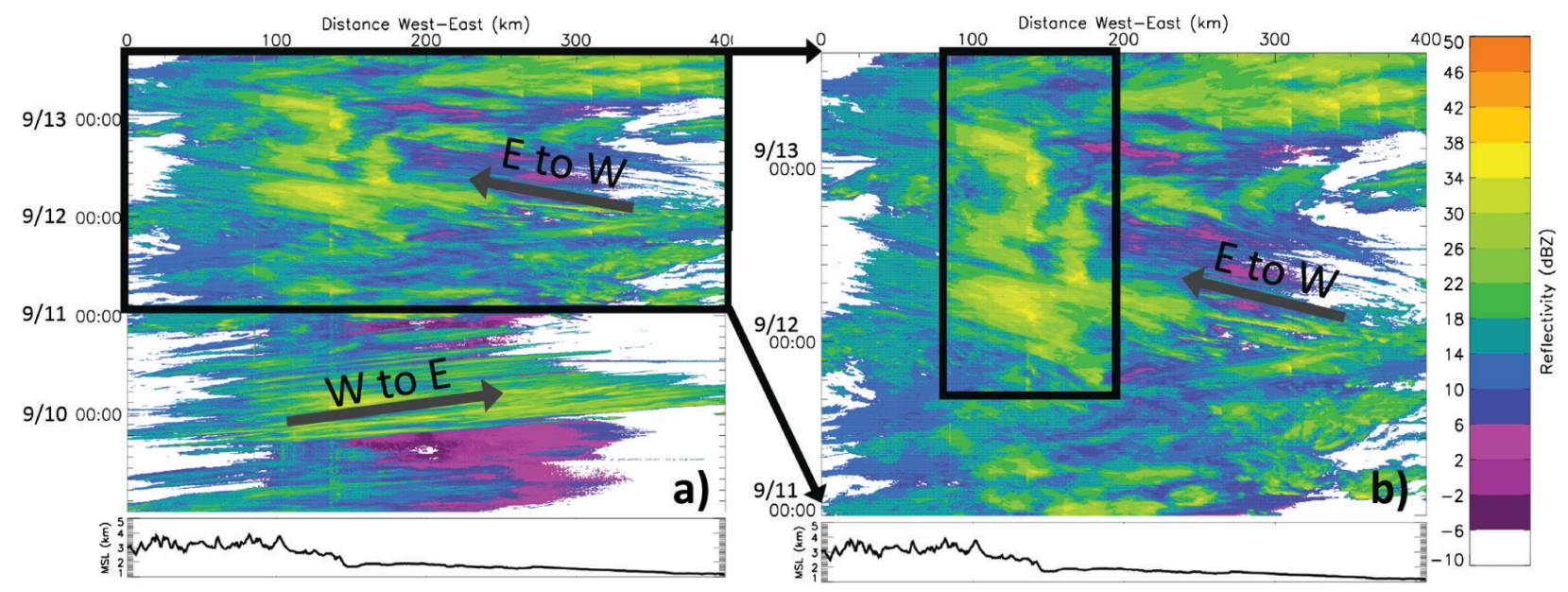

FIG. 6. Hovmöller (time-longitude) plots of Denver NEXRAD (KFTG) radar reflectivity for the area corresponding to Fig. 2: (a) 9-13 Sep and (b) II-13 Sep 2013. Inset dashed line box in (b) denotes period of heaviest rainfall and flash flooding. Solid arrows with letters indicate dominant directional movement of radar echoes (W-E is west to east, and E-W is east to west). The data are level-2 NEXRAD reflectivity data interpolated onto a 0.5 $\times 0.5 \times 0.5 \mathrm{~km}^{3}$ grid using the RADX software package. The mean topography averaged longitudinally $(\mathrm{N}-\mathrm{S})$ is shown along the bottom. 
ties. Finescale wind analyses were generated from the Variational Doppler Radar Analysis System (VDRAS; Sun and Crook 1997) for the main heavy rain episodes on 11-12 September (Fig. 7). Observations used by the VDRAS four-dimensional variational data assimilation (4DVar) system include radar radial velocity and reflectivity from NWS radars located in Denver (KFTG) and in Cheyenne, Wyoming (KCYS) and surface data from surface meteorological stations in the Rocky Mountain Front Range region. A movie loop of the VDRAS-analyzed convergence, horizontal wind at $0.15 \mathrm{~km}$ above ground level (AGL), and observed radar reflectivity for the period between 1800 UTC 11 September and 0800 UTC 12 September is provided in the supplemental information. The VDRAS analyses revealed a cyclonic mesoscale circulation in the southern part of the domain that gradually intensified from approximately 1800 to 2300 UTC 11 September. This circulation persisted, remaining relatively stationary, until around 0600 UTC 12 September and was associated with enhanced east-southeasterly flow in the region over Denver and Boulder. Although this circulation developed in the same general region as the "Denver cyclone" previously documented in the literature (e.g., Szoke et al. 1984; Wilczak and Christian 1990; Crook et al. 1990), ongoing research aims to determine whether the processes are similar. Strong convergence along with enhanced southeasterly winds (see the supplemental information) were present on the north side of the circulation, and a band of relatively deep convection developed within this region of enhanced upslope flow (Fig. 7). Observed reflectivity from a mosaic of KFTG (Denver) and KCYS (Cheyenne) WSR-88D echoes in excess of $30 \mathrm{dBZ}$ initiated near the center of this updraft region and then moved northwestward and also showed rotational signatures in between Denver and Boulder. The most intense and deepest convection (45-dBZ echo) occurred in Boulder County around 0600 UTC.

A second area of increased low-level convergence north of Fort Collins developed around 0200 UTC (Fig. 7; see the supplemental information). Around 0400 UTC, the two convective regions in Boulder and Larimer Counties appeared to converge, and

2200UTC, $9 / 11 / 2013$ 0000UTC, $9 / 12 / 2013$ O200UTC, 9/12/2013
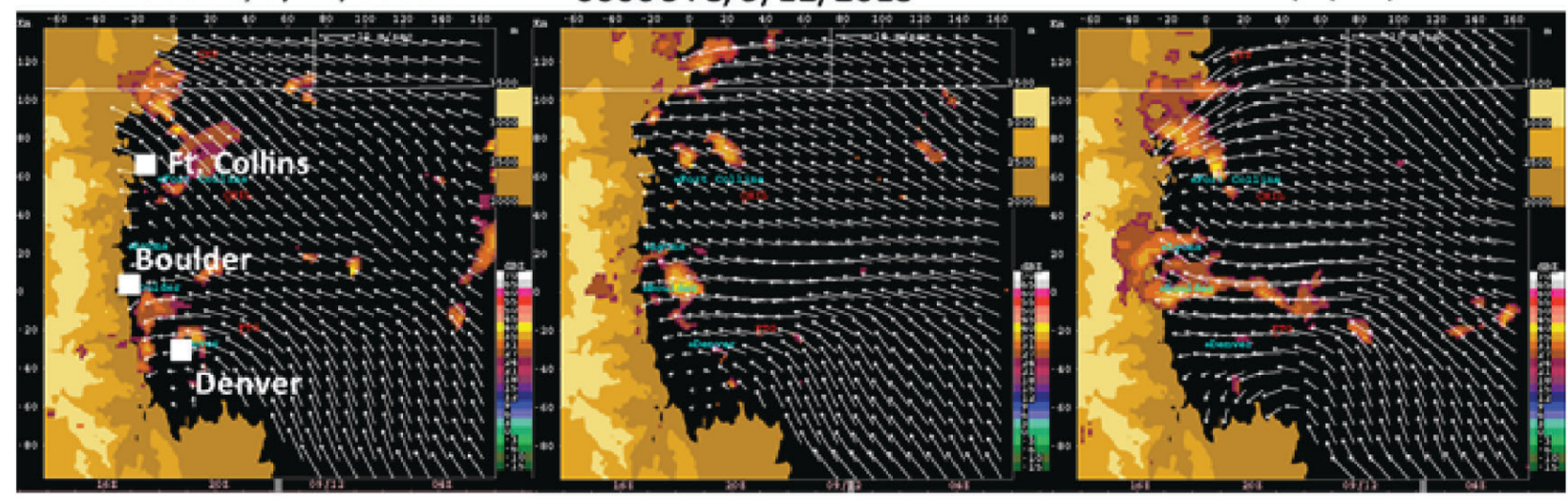

0400UTC, 9/12/2013

0600UTC, 9/12/2013

0800UTC, 9/12/2013

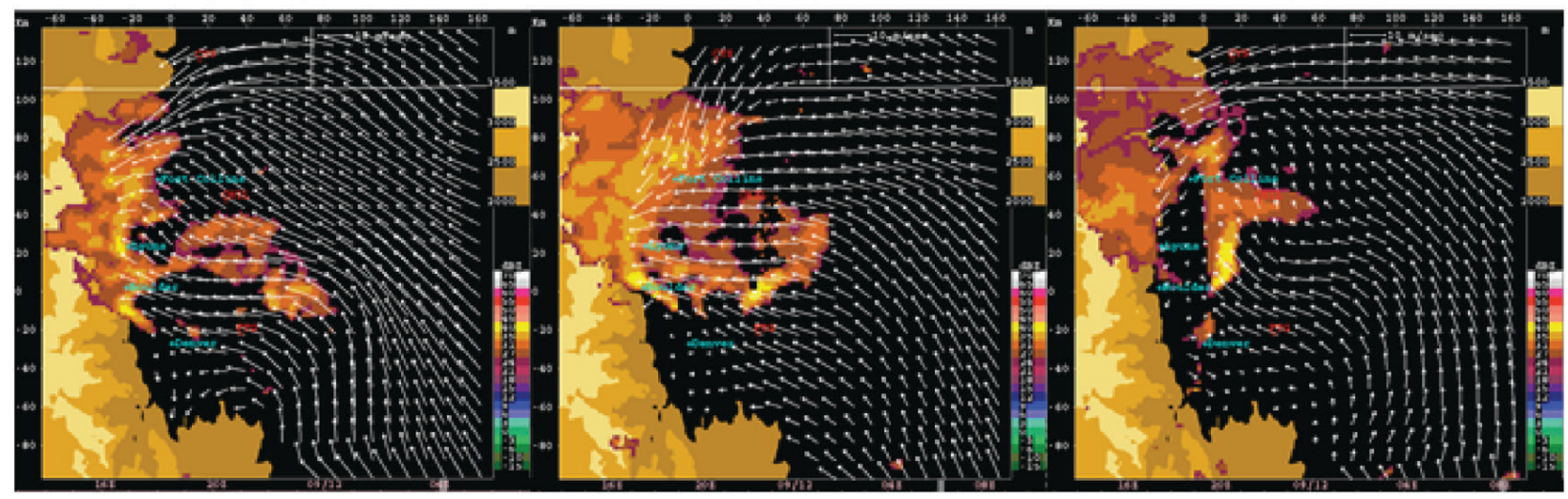

FIG. 7. VDRAS wind analysis (2 km MSL) at 2200 UTC II Sep and 0000, 0200, 0400, 0600 , and 0800 UTC I2 Sep. Static brown shading is topography, and purple-to-yellow shading is observed reflectivity from a mosaic of the KFTG (Denver) and KCYS (Cheyenne) WSR-88D radars. 
this merged region of heavy rain expanded northwestward from Boulder into the higher terrain near the town of Estes Park and northward along the mountain front. The period of 0400-0700 UTC was associated with peak hourly rainfall rates in excess of $45 \mathrm{~mm} \mathrm{~h}^{-1}$ observed from gauge data in the city of Boulder (Fig. 8). As discussed in the next section, this episode represented one of the few periods of vigorous, electrified, deep convection during the September 2013 rainfall event.

\section{CLOUDAND HYDROMETEOR PROCESSES.}

Much of the precipitation during the September 2013 Colorado flood was characterized by orographically lifted, stratiform precipitation with some embedded convection. During most of the event, a well-defined melting layer was present, and appreciable collisioncoalescence occurred between the melting layer and cloud base. Evidence for this comes from multiple observation platforms, including a vertically pointing, Ka-band, micro rain radar (MRR) located at Boulder, the NWS Denver Next Generation Weather Radar (NEXRAD) radar (KFTG), and the Colorado State University-University of Chicago-Illinois State
Water Survey (CSU-CHILL) dual-polarization Doppler radar located at Greeley (Fig. 9; also see Fig. 1 for locations of these instruments). As radar analysis indicates, stratiform precipitation was produced by ice particles falling through the melting layer and melting to form raindrops that continued to grow by collision-coalescence as they fell through a $2.5-\mathrm{km}$ deep warm cloud zone (Figs. 9, 10). Deep, saturated zones creating favorable conditions for collision-coalescence processes are uncommon in such highelevation, midlatitude, continental interior regions. Also, unlike most rain events along the Front Range occurring in September, the cloud bases during the highest precipitation periods were very low $(\sim 200 \mathrm{~m}$ AGL based on ceilometer observations shown in Fig. 10b). CSU-CHILL radar observations collected from 1500 UTC 12 September to 0400 UTC 13 September indicated a mean increase in reflectivity below the melting layer of about $1 \mathrm{dBZ} \mathrm{km}^{-1}$ toward the surface (Fig. 9). Differential reflectivity, the ratio between horizontal and vertical polarization reflectivity signals, from the CSU-CHILL radar increased by approximately $0.2 \mathrm{~dB} \mathrm{~km}^{-1}$ toward the surface during the same period, further supporting the assertion that

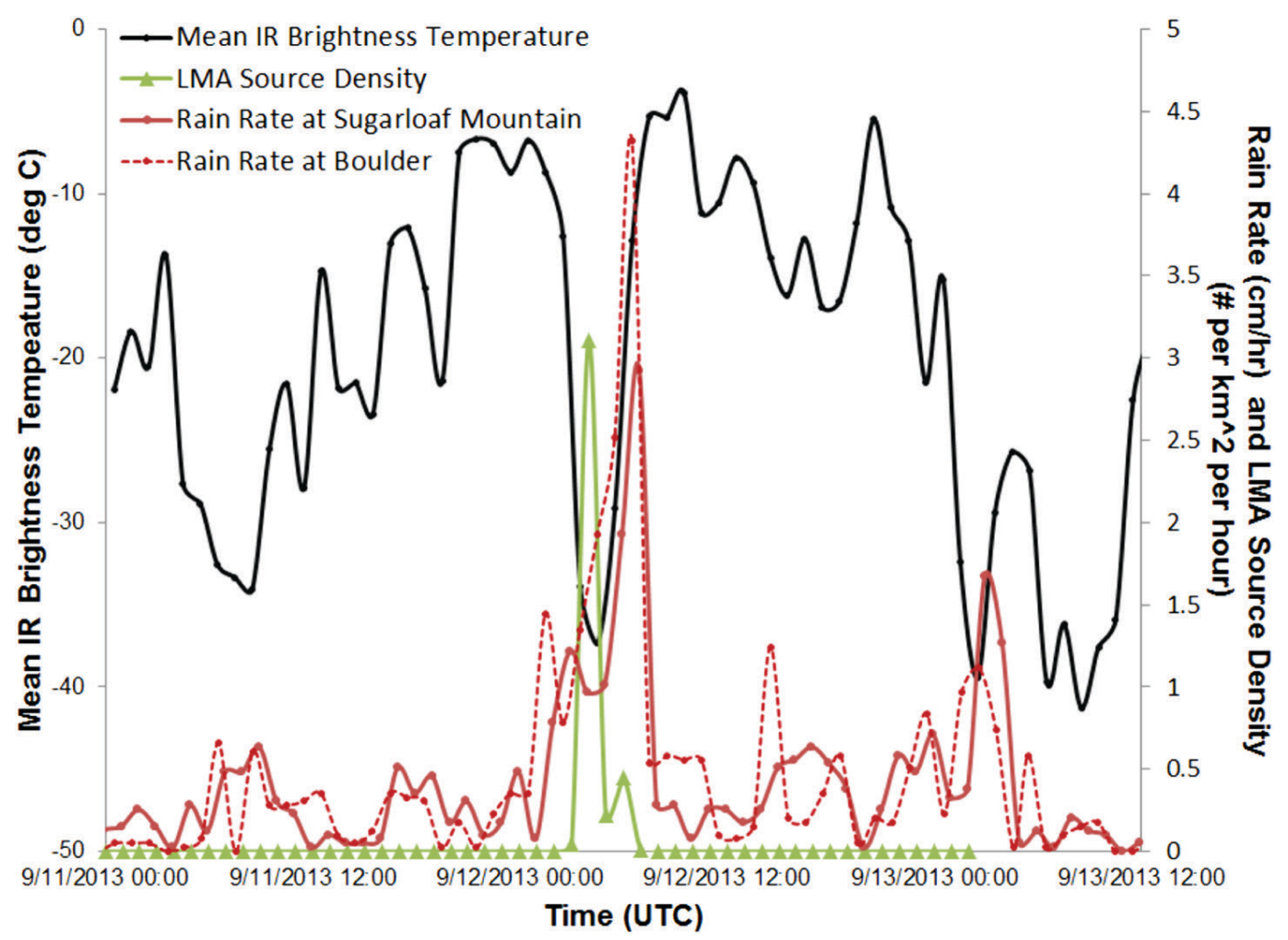

FIG. 8. Time series of mean infrared brightness temperature from the GOES-I3 satellite (black line) within a $10-\mathbf{k m}$ radius of Boulder, lightning source density within a $20-\mathbf{k m}$ radius around Boulder from the Colorado Lightning Mapping Array (green line), and rainfall rates $\left(\mathrm{cm} \mathrm{h}^{-1}\right)$ observed at Boulder and Sugarloaf (red lines). 
Distance from the CSU-CHILL radar (km)

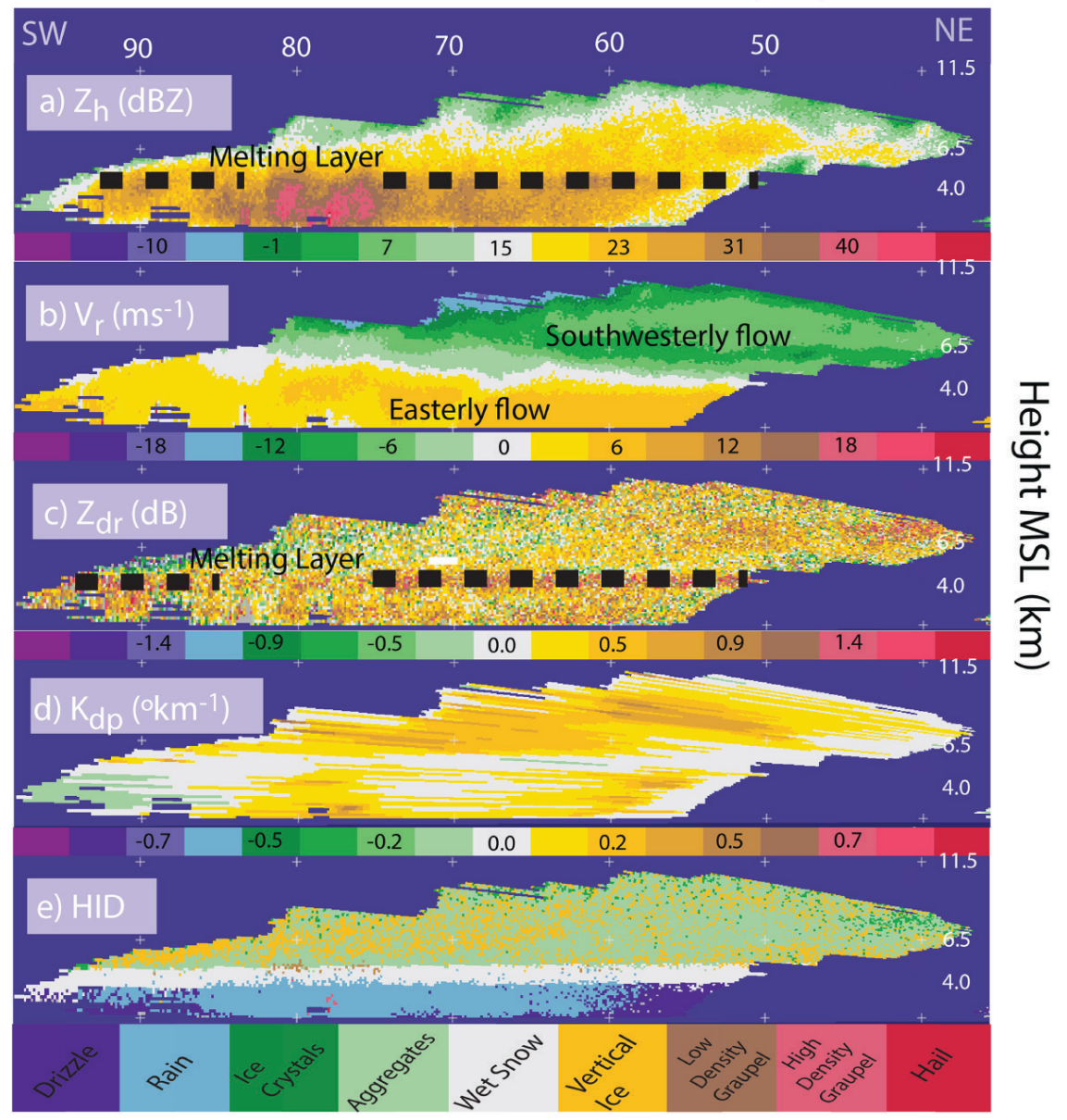

FIG. 9. Vertical cross section of (a) reflectivity $\left(Z_{b}\right)$, (b) radial Doppler velocity $\left(V_{r}\right)$, (c) differential reflectivity $\left(Z_{d r}\right)$, (d) specific differential phase $\left(K_{d p}\right)$, and $(e)$ hydrometeor classification (HID) observed by the CSU-CHILL S-band radar at 2323 UTC 12 Sep. The radar was scanning toward the southwest $\left(225^{\circ}\right)$ from the radar location over a distance of approximately $90 \mathrm{~km}$. and the Geostationary Operational Environmental Satellite-13 (GOES-13) infrared data, also plotted in Fig. 8, showed a deep convective signal with a minimum brightness temperature of $-51^{\circ} \mathrm{C}$ during that time. Outside of this time period, evidence of deep convection was generally lacking. Infrared satellite imagery showed periods of shallower convection (cloud tops warmer than $-40^{\circ} \mathrm{C}$ ) during the afternoon hours of 12 September. Some of the shallow convection appeared to produce intense warm rain showers without a well-defined bright band (Fig. 9 at a distance of 75-80-km range from the CHILL radar). For most of the time period, radar-estimated cloud-top heights ranged between 8 and $13 \mathrm{~km}$ MSL.

Particularly intense periods of precipitation in Boulder and Larimer Counties occurred in bands of high rainfall rates during two distinct episodes: the aforementioned 0000-0600 UTC period cloud droplets slowly grow to small raindrops as they fall to the surface. Even though for the period shown in Fig. 9 there is a general small increase in reflectivity $Z$ and differential reflectivity $Z_{\mathrm{dr}}$ toward the ground indicating drop growth, mean $Z_{\mathrm{dr}}$ values (and hence drop sizes) are still on average smaller than usual for Front Range warm-season rains (see Fig. SB3b) and below the thresholds for quantitative precipitation analysis in the polarimetric retrieval algorithm used here ( $>0.5 \mathrm{~dB}$ for $Z_{\mathrm{dr}}$; Cifelli et al. 2011).

During the period of relatively deep convection in Boulder County from 0000 to 0600 UTC 12 September, occasional lightning was observed by the Northeast Colorado Lightning Mapping Array (LMA; Fig. 8). In addition, KFTG hydrometeor classification indicates low-density graupel close to the melting layer (see Fig. A2 for vertical profiles of hydrometeor classifications from the CSU-CHILL and KFTG radars), and a second period between 2200 UTC 12 September and 0300 UTC 13 September. During these periods, peak rainfall rates of up to $50-70$ and $40-60 \mathrm{~mm} \mathrm{~h}^{-1}$, respectively, were observed from multiple surface rain-gauge stations (Figs. 8, 10). Rainfall observed by quality-controlled Particle Size and Velocity (PARSIVEL; Ott, Inc.) optical disdrometers was much higher in Boulder (1,665 m MSL) and Marshall (1,742 m; $5 \mathrm{~km}$ south of Boulder) compared to two PARSIVEL instruments located $12 \mathrm{~km}$ farther to the west in the foothills at Sugarloaf $(2,431 \mathrm{~m} \mathrm{MSL})$ and Melvina Hill (2,225 m MSL). The two intense episodes on 12 September were characterized by smaller reflectivity values, which rarely exceeded $45 \mathrm{dBZ}$, and were consistent with the relatively small raindrop sizes observed, with mean diameters ranging mainly between 1 and $1.8 \mathrm{~mm}$ (Fig. 10c). The reflectivity-rainfall $\left(Z-R ; Z\right.$ in $\left.\mathrm{mm}^{6} \mathrm{~m}^{-3}\right)$ relationship derived from the 


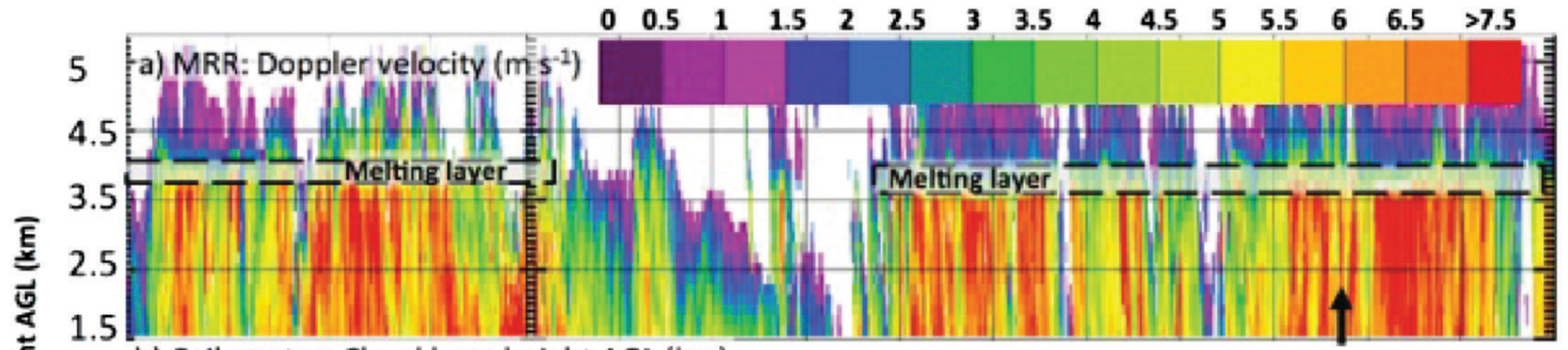

b) Ceilometer: Cloud base height AGL $(\mathrm{km})$

$0.6 \mathrm{~N}$

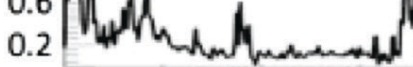

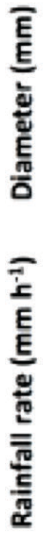

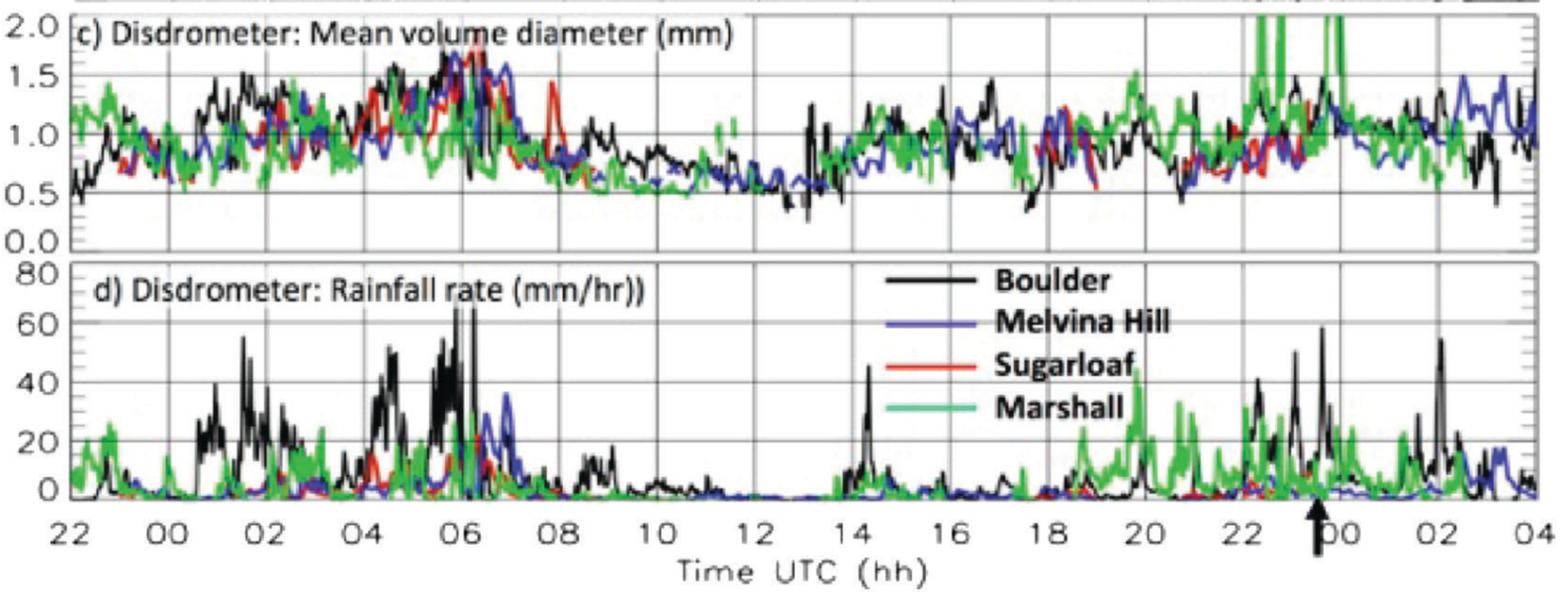

FIG. I0. (a) Vertical profile of Doppler velocity observed by a vertically pointing MRR. Approximate location of the melting layer is indicated by dashed lines. MRR was located in Boulder at $1.66 \mathrm{~km} \mathrm{MSL}$. (b) Height of the lowest cloud base measured by a ceilometer. (c),(d) Mean volume drop diameter and rainfall rate observed by surface disdrometers in Boulder and the Foothills. Note that the Sugarloaf disdrometer was not operating between 0800 and 1800 UTC on 12 Sep and 13 Sep. Black arrows in (a) and (d) indicate the time of the radar observations shown in Fig. I. All data were plotted at I-min resolution.

disdrometer observations (Fig. SB3; Boulder: $132 R^{1.3}$; Marshall: $106 R^{1.3}$; Melvina Hill: $120 R^{1.5}$; and Sugarloaf: $\left.149 R^{1.4}\right)$ indicates that the rainfall did not show typical characteristics of midlatitude rain but instead showed strongly tropical rainfall characteristics, a feature also observed during the Fort Collins flash flood in 1997 (Petersen et al. 1999). A more detailed characterization of hydrometeors observed during the event and their impact on polarimetric radar data are provided in the sidebar on "Raindrop structure and polarimetric radar data."

HYDROLOGIC PROCESSES AND IMPACTS.

Rainfall-induced flooding in the Rocky Mountain region of the United States has been well documented (e.g., Michaud et al. 2001), including extreme events such as the Rapid City, South Dakota, flash flood of June 1972 that resulted in 220 fatalities, the Big Thompson flash flood of July 1976 (Caracena et al. 1979; Maddox et al. 1978) that resulted in 144 fatalities, and the Fort Collins flash flood of July 1997 (Petersen et al. 1999) that resulted in 5 fatalities and \$200 million in damage. Long-term historical data show an event similar to September 2013 took place in the same region in September 1938, though there is little information available on the hydrometeorological details surrounding that event (BASIN 2014).

A key challenge in providing confident estimates of peak flows during many flood events is the fact that streamflow gauges along the most heavily flooded river systems were destroyed or experienced river stages that exceeded established river stage-streamflow relationships [i.e., "rating curves" - see NWS (2014) for additional information on the issue of rating curves during the September 2013 flood event]. Since the flood event, several reports have been released that have attempted to summarize, by means of post-flood peak flow reconstruction methods or recalibrated rating curves, peak flow conditions during the flood along with estimates of the statistical 


\section{RAINDROP STRUCTURE AND POLARIMETRIC RADAR DATA}

The prevalence of small and nearly spherical raindrops is evident in the dual-polarization measurements from the CSU-CHILL radar as well as in disdrometer dropsize distributions derived using the transition ( $\mathrm{T}$ matrix) method (Waterman 1965; Mishchenko et al. 1996; Vivekanandan et al. 1991; Bringi and Chandrasekar 200I). Small, nearly spherical raindrops contribute comparatively little information to polarimetric radar signals such as differential reflectivity $\left(Z_{\mathrm{dr}}\right)$ and specific differential phase shift $\left(K_{\mathrm{dp}}\right)$.
The $Z_{\mathrm{dr}}$ values observed by the CSU-CHILL radar during the second episode (2200-0300 UTC I 2 Sep) were generally less than I $\mathrm{dB}$, though higher values were also observed (Fig. SB3b). For the highest observed reflectivities of about $45 \mathrm{dBZ}$ from the CSU-CHILL radar (Fig. SB3c), the mean observed $Z_{d r}$ value is around I dB.This approximately corresponds to the mean mass-weighted equivalent sphere drop diameter $D_{m} \approx 0.16 \mathrm{~cm}$ (I.6 $\mathrm{mm}$ ), according to an average $D_{m}-Z_{\mathrm{dr}}$ relation [e.g., a)

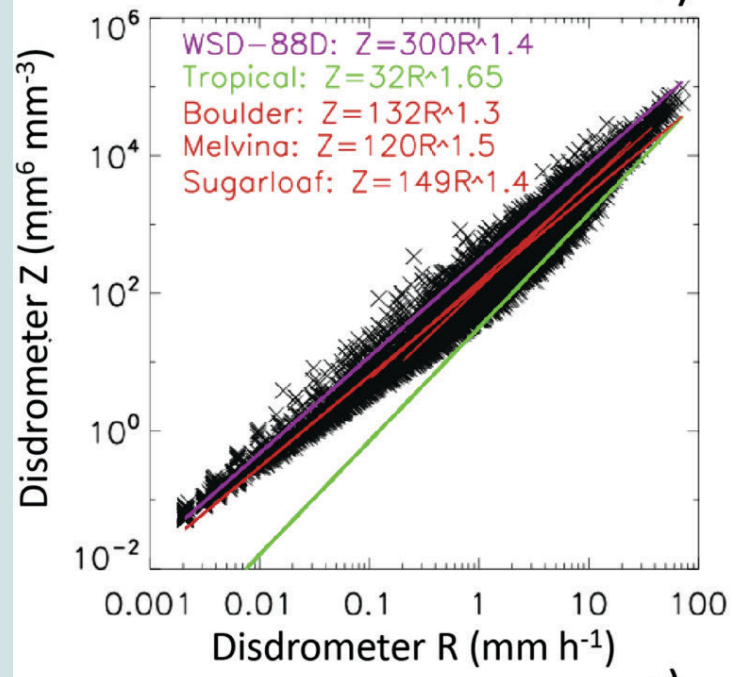

c)

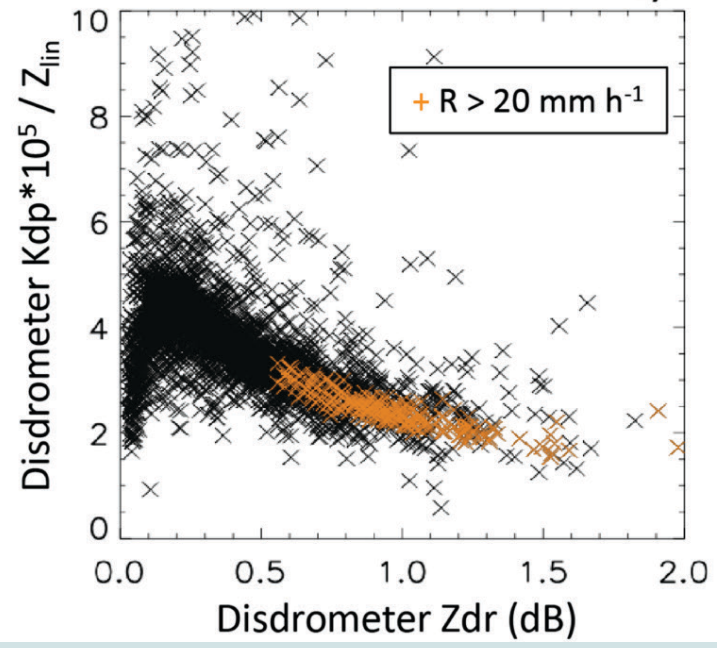

b)

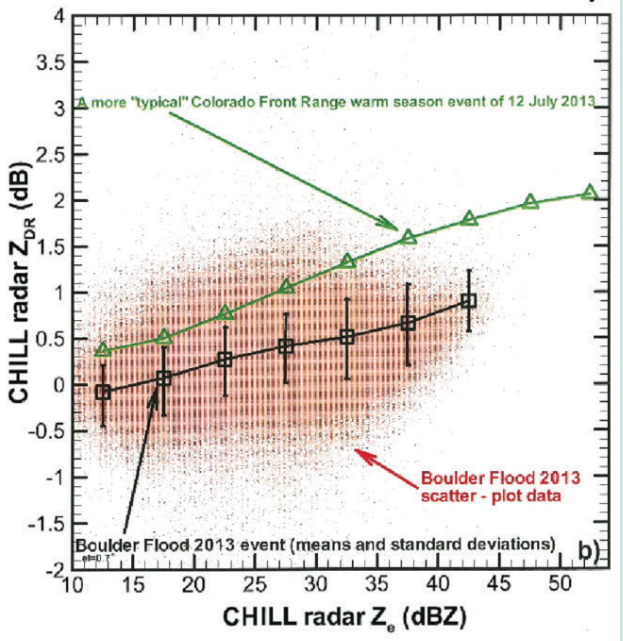

FIG. SB3. Scatterplots showing ratios of (a) disdrometer-based $Z-R$, (b) $Z_{d r}-Z$ relationship based on CHILL radar observations, and (c) disdrometer-based $K_{\mathrm{dp}} I Z-Z_{\mathrm{dr}}$ relationship. Disdrometer data are based on period shown in Fig. 6 (30 h). CSU-CHILL radar data were analyzed between 1550 UTC 12 Sep and 0240 UTC 13 Sep. The data in (a) and (c) are based on measurements at Boulder, Melvina Hill, and Sugarloaf. Red, green, and purple lines in (a) represent Z- $R$ relationships for the flood event based on three disdrometers, tropical rainfall, and non-tropicalconvective precipitation used by the WSD-88D radar, respectively. (b) Green and black line represent typical mean values for a typical warm-season rain event in the Front Range and for the September 2013 flood event. Orange X's in (c) represent times when rainfall exceeded $20 \mathrm{~mm} \mathrm{~h}^{-1}$. 
$D_{m}(\mathrm{~cm})=0.16 Z_{\mathrm{dr}}^{0.49}(\mathrm{~dB})$; Bringi and Chandrasekar 200I; Matrosov et al. 2006] and is in good agreement with the PARSIVEL data (Fig. SB3b) and with the KFTG polarimetric data for periods when there is overlapping data. It is noted that larger $Z_{\mathrm{dr}}$ values (i.e., slightly larger, more oblate raindrops) were observed during the more convective times when rainfall rates exceeded 20 $\mathrm{mm} \mathrm{h}^{-1}$ (indicated by orange plus signs in Fig. SB3c). As a comparison, Fig. SB3b also shows the mean CSU-CHILLderived $Z-Z_{d r}$ relation for a 12 Jul 2013 rainfall event with much higher mean $Z_{\mathrm{dr}}$ values ranging up to $2 \mathrm{~dB}$, which is more typical for rainfall along the Colorado Front Range. This distinction between tropical-like, narrow drop-size distributions and more typical diurnal convection drop-size distributions was noted by Bringi et al. (2003), Petersen et al. (1999), and Kennedy et al. (200I) in their respective analyses of other events including the $1997 \mathrm{Ft}$. Collins flood event. Despite the small raindrops and low reflectivity, high values of $K_{\mathrm{dp}} I Z$ (where $Z$ is in linear form) indicate large water contents with low reflectivity and small $Z_{\mathrm{dr}}$ values (Fig. SB3c). Because of the large concentration of small drops (and low $Z_{d r}$ values) and the atypical $Z-R$ relationship for the September flood event, the operational single- and dual-polarization NEXRAD radar rainfall estimates had difficulty in developing accurate rainfall estimates. probability or recurrence intervals (e.g., Yochum and Moore 2013; Stewart 2013; Houck 2014; NWS 2014). An abbreviated synthesis of these peak flow values is provided in Table 1, and locations of peak flow values for a host of river systems are also shown in Fig. 1. Because peak flow values on any given river system are controlled to a large degree by the total contributing area of a river's watershed, peak flow values are often normalized by watershed area to facilitate the intercomparison of peak flows between watersheds (i.e., unit discharges), and thus unit discharge values are also provided in Table 1. It is important to note that there are considerable uncertainties in peak flow and return flow estimates because of the dynamic nature of flooding events themselves, debris suspended in the flow, rapidly changing channel geometries, assumptions involved in flow velocity conditions during the flood, and the statistical uncertainty inherent in characterizing extreme or rare events.

From south to north, the worst-affected systems were Fourmile Canyon in the Boulder Creek watershed, James Creek and Lefthand Creek within and downstream of Jamestown, both the south and north branches of the St. Vrain River feeding into Lyons, the Little Thompson River, Fish Creek, the upper Big Thompson River and Fall Creek near Estes Park, the North Fork and mainstem of the Big Thompson River, Buckhorn Creek, and portions of the Cache la Poudre River (see Fig. 1 for map of principal watersheds). Regions impacted by recent wildland fires (see Fig. 1 for map of recent burn areas) tended to exhibit particularly high unit discharge values (e.g., the Skin Gulch drainage in the Poudre River watershed, Buckhorn Creek in the Big Thompson watershed, and Fourmile Creek in the Boulder Creek watershed). The reasons for such extreme hydrologic responses in burn areas are manifold, including removal of vegetation that intercepts rainfall, reduction in surface ponding or "storage" capacity, a reduction in surface roughness to overland flow, and potential reductions in soil infiltration capacity caused by soil chemical and physical responses to extreme heat during the fires [see Moody et al. (2013) for a review on fire-hydrology interactions].

As flood waves propagated out onto the plains, several communities there suffered massive damage. The worst-affected river systems on the Colorado plains were the St. Vrain River through Longmont; the Big Thompson River through Loveland; Westerly Creek and Sand Creek; north of Denver; and the South Platte River through the towns of Kersey, Milliken, and Evans (all near Greely in Fig. 1). Local flooding was widespread throughout several small urban channel systems, and many rural, agricultural properties and communities were hard hit by flooding on the plains (Stewart 2013; NWS 2014).

Infrastructure to manage water resources and floodwaters throughout the region has largely girded the region from recent widespread flooding impacts. The events of September 2013 exposed several vulnerabilities in the regional flood protection infrastructure, but a large number of flood control structures did perform according to their design and likely prevented additional losses in lives and property (Stewart 2013). Table 1 provides the most recent estimates on the long-term event probabilities or "return periods" available for this event that have been compiled from various sources. On the mainstem and North Forks of the Big Thompson River the flood has been estimated to have a return period around 500 years (i.e., $1 / 500$ or $0.2 \%$ probability), as did parts of the lower St. Vrain River near Lyons, Colorado (Houck 2014). On Boulder Creek the estimate of a 50-yr flood was less exceptional, owing to the fact that the heaviest rain 


\begin{tabular}{|c|c|c|c|c|c|}
\hline \multirow[b]{2}{*}{ Streamflow station } & \multirow{2}{*}{$\begin{array}{c}\text { Estimated } \\
\text { peak flow } \\
\mathrm{ft}^{3} \mathrm{~s}^{-1}\left(\mathrm{~m}^{3} \mathrm{~s}^{-1}\right)\end{array}$} & \multirow{2}{*}{$\begin{array}{c}\text { Estimated } \\
\text { unit discharge } \\
{\left[\left(\mathrm{ft}^{3} \mathrm{~s}^{-1}\right) \mathrm{mi}^{-2}\right]} \\
{\left[\left(\mathrm{m}^{3} \mathrm{~s}^{-1}\right) \mathrm{km}^{-2}\right]}\end{array}$} & \multirow{2}{*}{$\begin{array}{l}\text { Basin area } \\
\mathbf{m i}^{2}\left(\mathbf{k m}^{2}\right)\end{array}$} & \multicolumn{2}{|c|}{$\begin{array}{c}\text { Estimated event } \\
\text { probability }\end{array}$} \\
\hline & & & & (\%) & Source \\
\hline I. Coal Creek at Plainview & $3,900(110)$ & $258(2.82)$ & I5.I (39.1) & $>1 \%$ & CWCB \\
\hline \multicolumn{6}{|l|}{ Boulder Creek } \\
\hline 2. Fourmile Creek at Orodell & $2,733(77.4)$ & $112(1.24)$ & $24.2(62.7)$ & $\mathrm{N} / \mathrm{A}$ & CWCB \\
\hline 3. Boulder Creek at Orodell & $2,020(57.2)$ & $19.8(0.22)$ & $102(264)$ & $\mathrm{N} / \mathrm{A}$ & CWCB \\
\hline 4. Boulder Creek at 28th Street & $5,300(150)$ & $39.0(0.43)$ & $136(352)$ & $4 \%$ & CWCB \\
\hline \multicolumn{6}{|l|}{ James and Lefthand Creeks } \\
\hline 5. James Creek at Jamestown & $4,800(136)$ & $350(3.8)$ & $13.7(35.5)$ & $0.30 \%$ & NRCS \\
\hline 6. Litte James upstream of Jamestown & $1,800(51.0)$ & $578(6.3)$ & $3.11(8.05)$ & $0.30 \%$ & NRCS \\
\hline 7. Lefthand at mouth & $3,520(99.7)$ & & $\mathrm{N} / \mathrm{A}$ & $1 \%$ & CWCB \\
\hline \multicolumn{6}{|l|}{ St. Vrain River } \\
\hline 8. Middle St. Vrain above S. St. Vrain & $1,750(49.6)$ & $54(0.59)$ & $32.4(83.9)$ & $1 \%-2 \%$ & CWCB \\
\hline 9. South St. Vrain at Middle St. Vrain & $2,700(76.5)$ & $40(0.44)$ & $66.7(173)$ & $2 \%$ & CWCB \\
\hline 10. South St. Vrain above North St.Vrain & $9,000(255)$ & $98(1.1)$ & $92(238)$ & $>0.2 \%$ & CWCB \\
\hline II. North St. Vrain above South St. Vrain & $12,300(348)$ & $98(1.1)$ & $125(323)$ & $<0.2 \%$ & CWCB \\
\hline 12. St.Vrain at Lyons & $19,600(555)$ & $90(0.99)$ & $216(559)$ & $>0.2 \%$ & CWCB \\
\hline 13. St.Vrain at Interstate 25 & $18,000(509)$ & $21(0.23)$ & $854(2,211)$ & $<1 \%$ & CWCB \\
\hline \multicolumn{6}{|l|}{ Little Thompson } \\
\hline 14. Little Thompson at Pinewood Springs & $14,600(4 \mid 3)$ & $314(3.4)$ & $46.4(120)$ & $0.33 \%$ & NRCS \\
\hline 15. Little Thompson at Interstate 25 & $\mid 4,500(4 \mid I)$ & $85(0.9)$ & $170(440)$ & $0.20 \%$ & CWCB \\
\hline \multicolumn{6}{|l|}{ Big Thompson } \\
\hline 16. Fish Creek near Estes Park & $6,900(195)$ & $442(4.8)$ & $15.6(40.4)$ & $0.20 \%$ & NRCS \\
\hline 17. Fall River upstream of Estes Park & $3,800(108)$ & $104(1.1)$ & $36.5(94.5)$ & $0.50 \%$ & NRCS \\
\hline 18. Big Thompson at Drake above N. Fork & $12,500(354)$ & $65(0.7)$ & $191(495)$ & $0.20 \%$ & CWCB \\
\hline 19. Big Thompson below Drake & $29,500(835)$ & $107(0.7)$ & $274(709)$ & $0.20 \%$ & CWCB \\
\hline 20. North Forth Big Thompson at Drake & $18,400(52 \mid)$ & $259(1.2)$ & $70.9(184)$ & $0.40 \%$ & CWCB \\
\hline $\begin{array}{l}\text { 21. North Forth Big Thompson near } \\
\text { Glen Haven }\end{array}$ & $\mathrm{I}, 700(48 . \mathrm{I})$ & $93(2.8)$ & $18.2(47.1)$ & $1 \%-2 \%$ & NRCS \\
\hline 22. Buckhorn Creek at Masonville & $\mathrm{II}, 000(3 \mathrm{II})$ & $124(1.3)$ & $88.2(228)$ & $1 \%-2 \%$ & NRCS \\
\hline \multicolumn{6}{|l|}{ Cache la Poudre } \\
\hline $\begin{array}{l}\text { 23. Skin Gulch upstream of Stove } \\
\text { Prairie Road }\end{array}$ & $2,500(70.8)$ & $714(7.8)$ & $3.5(9.06)$ & $0.20 \%$ & NRCS \\
\hline $\begin{array}{l}\text { 24. Young Gulch upstream of state highway } \\
\text { CO-I4 }\end{array}$ & $1,200(34.0)$ & $79.0(1.4)$ & $15.2(39.4)$ & $2 \%-4 \%$ & NRCS \\
\hline \multicolumn{6}{|l|}{ South Platte River } \\
\hline 25. South Platte at Ft. Lupton & $10,100(286)$ & $2(0.02)$ & $5,043(13,056)$ & $10 \%$ & CWCB \\
\hline 26. South Platte at Kersey & $55,000(1,557)$ & $5.7(0.06)$ & $9,659(25,007)$ & $0.20 \%$ & CWCB \\
\hline
\end{tabular}


fell in the lower and flatter portions of the drainage where runoff production was not as efficient or rapid.

RUNOFF GENERATION MECHANISMS.

While the spatial distribution and intensity patterns of rainfall played the dominant role in dictating the timing and severity of flooding in specific drainages, the evolution of runoff and flooding was also influenced by land surface characteristics, both natural and human engineered. Many flood-affected regions of the 2013 Colorado floods are characterized by large variations in slope, soil types, soil thickness, land use, and forest cover. Several of the most severely impacted drainages of the Colorado Front Range were those that received the heaviest rainfall in mountainous portions of their drainage areas (e.g., Fourmile Creek, Lefthand Creek, St. Vrain River, and Big and Little Thompson Rivers). As the flooding from the mountain front channel systems spilled onto the plains and merged into the mainstem of the South Platte River, several communities along its path were inundated for several days after rainfall had ceased. Rising groundwater levels from perched, unconfined aquifers throughout the Front Range also created domestic flooding hazards as water percolated into basements of buildings, suggesting that many regional soils became saturated. In total, the time it took from the start of severe flooding to occur in the tributary drainages until the flood wave was attenuated to below flood stage levels on the South Platte River in western Nebraska was approximately two weeks (as indicated by USGS streamflow observations for the South Platte River at Roscoe, Nebraska). As such, the September floods of 2013 transcended several time scales of flooding from short-term "flash floods" on the order of tens of minutes all the way out to "slow rise" floods on the order of days to weeks. This time-scale transcendence of severe flooding impacts was one of the unique characteristics of this event.

The range in flooding responses suggests that multiple flood generation mechanisms were operating during this prolonged event. There were likely numerous areas of "infiltration excess" (i.e., where rainfall rates exceed soil infiltration rates) runoff mechanisms operating during some of the heavy rainfall that occurred the night of 11-12 September (Yochum and Moore 2013; Coe et al. 2014; NWS 2014). Fast runoff responses to heavy rain were widespread in steep canyon areas with little or no soil cover as well as in recently burned areas. However, as rainfall persisted, and as evidenced by the aforementioned groundwater impacts and by in situ soil moisture measurements (see soil moisture measurements from the University of Colorado Mountain Research Station in Fig. A3), soils appeared to approach saturated conditions from the plains all the way up to $3,300 \mathrm{~m}(10,000 \mathrm{ft}) \mathrm{MSL}$. Under such saturated soil conditions, there is an increased likelihood of "saturation excess" runoff generation mechanisms (i.e., where nearly saturated soils have very little capacity to absorb more water). Additionally, across most of the Front Range river system, streamflow recession (i.e., the time it takes for streamflow to return to more normal seasonal values) lasted for months after the September event. The late autumn/early winter period is usually a time when many Front Range river systems are at their lowest flow levels or run dry. However, many of these systems carried appreciable flow into January 2014 (not shown) compared with more typical seasonal flow values that potentially have a cross-seasonal impact on streamflow production during snowmelt in the following spring.

\section{ANALYSIS OF QUANTITATIVE PRECIPI- TATION ESTIMATION PRODUCTS. The} backdrop of steep, complex topography along with the predominance of low-altitude cloud bases with high concentrations of small-to-medium, nearly spherical raindrop sizes presented a major challenge for operational QPE products that resulted in significant uncertainty as to how much rain was falling and where. Figure 11 shows the 2-day total rainfall from five different QPE products derived from level-2 NWS NEXRAD radar data at surface rain-gauge sites and illustrates the large uncertainties that existed among the QPE products. These products include three "radar only" products where the difference between the products was the selection of the radar reflectivity rainfall $(Z-R)$ relationship (KFTG default or tropical) or the use of multiparameter polarimetric radar information (KFTG dual-polarization). The default regional $Z-R$ relationship for the Denver NEXRAD radar (KFTG) is $Z=300 R^{1.4}$. An aggressive "tropical" rainfall $Z-R$ relationship of $Z=32 R^{1.65}$ (J. Wilson 2013, personal communication) was also used for comparison. The polarimetric radar QPE product is developed by the NWS after Ryzhkov et al. (2005). The other two rainfall products shown are two gauge-corrected products produced by National Oceanic and Atmospheric Administration (NOAA) entitled the Multisensor Precipitation Estimate (MPE; Kitzmiller et al. 2013) and National Centers for Environmental Prediction (NCEP) stage IV (Lin and Mitchell 2005). The two gauge-corrected products 
(a) KFTG Default Z-R

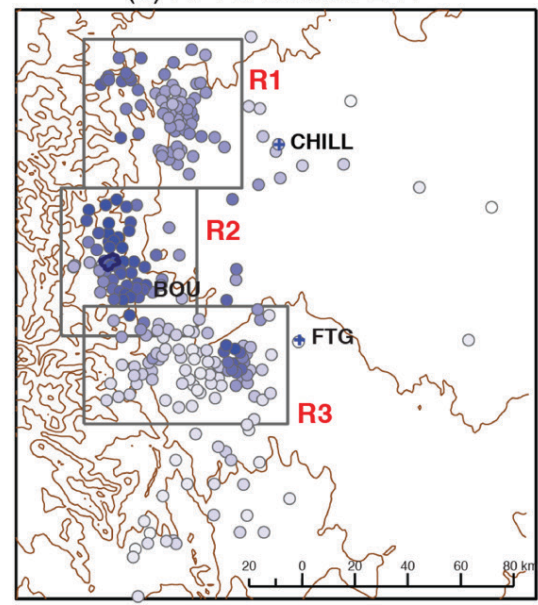

(d) MPE
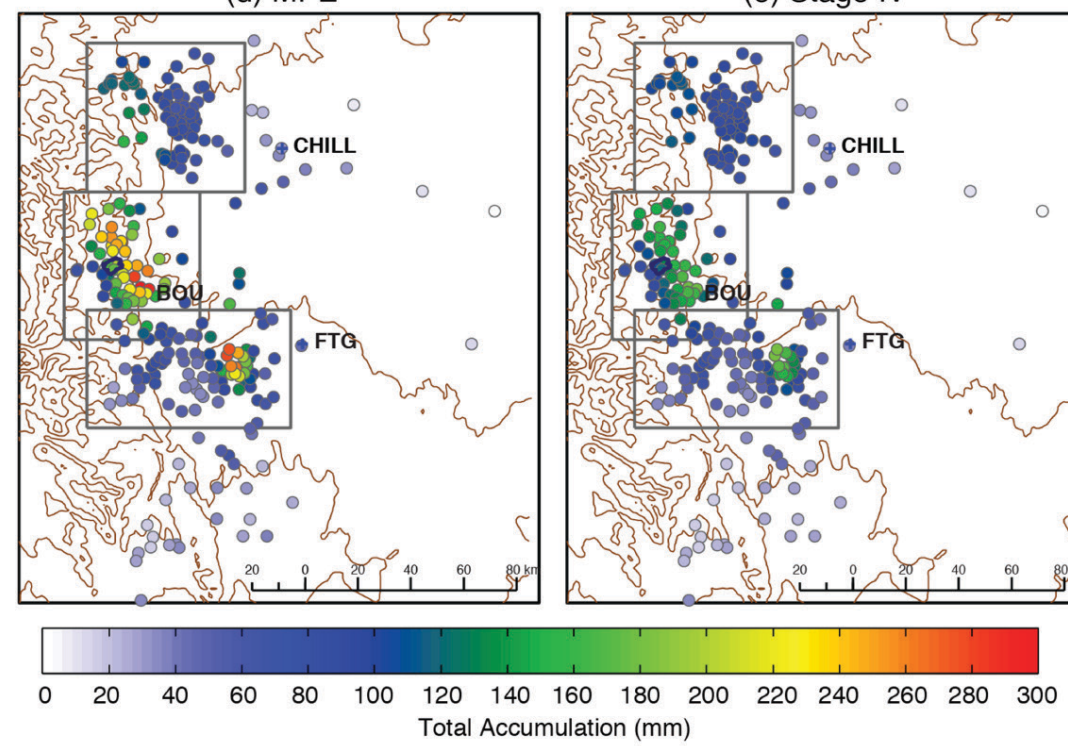

(b) KFTG Tropical Z-R

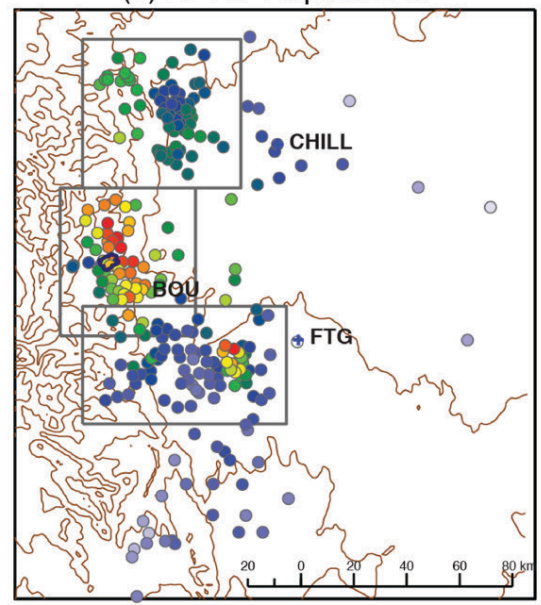

(e) Stage IV

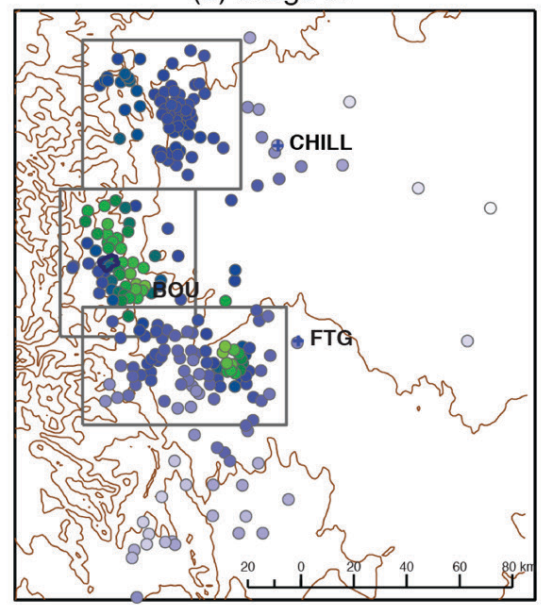

r

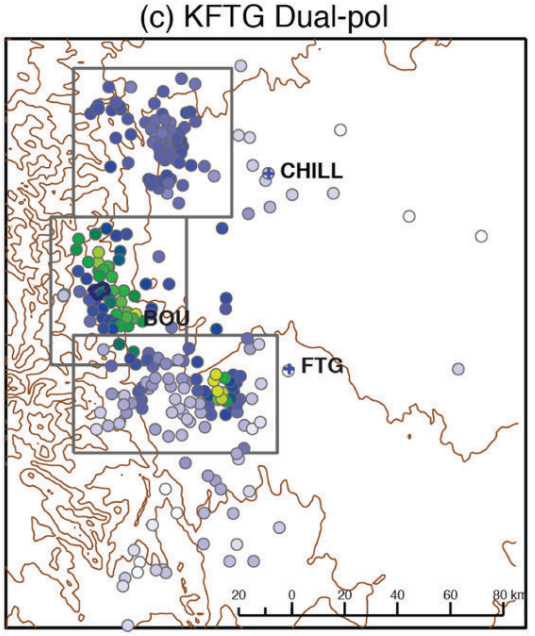

(f) Observation

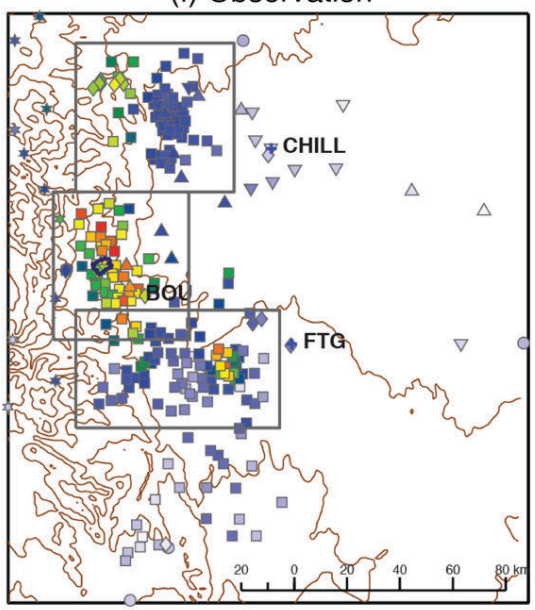

ALERT

Northern Water

- CoAgMet

USCRN

SNOTEL

Research gauges/parsivels

FIG. II. Point station comparisons of 2-day (0000 UTC II Sep-0000 UTC I3 Sep) total rainfall from five different QPE products and observations: (a) KFTG default Z-R, (b) KFTG tropical Z-R, (c) KFTG dual-pol-based estimates, (d) MPE, (e) stage IV, and (f) observations. Observations consist of a combination of operational and research data networks and have been manually quality controlled. A summary of the 2-day total accumulation and bias for three enclosed regions (inset boxes) is given in Fig. A4.

differ by both the number of stations used in the analysis and their quality control and bias correction procedures. With respect to the application or use of these products, it is important to note that the radar-only QPE products are available in real-time minutes after the radar completes its scan, while the gauge-corrected products have latencies on the order of 1-2 days. The QPE values at rain-gauge sites were determined by mapping the five QPE products over a common grid space (1-km horizontal grid spacing) and then taking an inverse distant-weighted average of grid cell values from a $3 \mathrm{~km} \times 3 \mathrm{~km}$ area centered on the nearest grid point from each gauge site using the Model Evaluation Tools (MET) software (DTC 2014b).

Bias maps shown in Fig. 12 and a summary table of QPE biases (Table 2), separated by three subregions shown as inset boxes R1, R2, and R3 in Figs. 11 and 12, highlight large discrepancies between these products, particularly in subregion two but also in other areas. It is clear that the default regional NEXRAD $Z-R$ relationship is not 
(a) KFTG Default Z-R

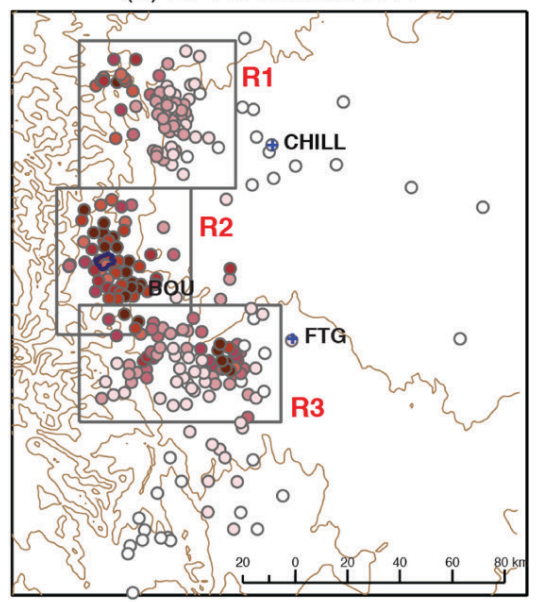

(d) MPE

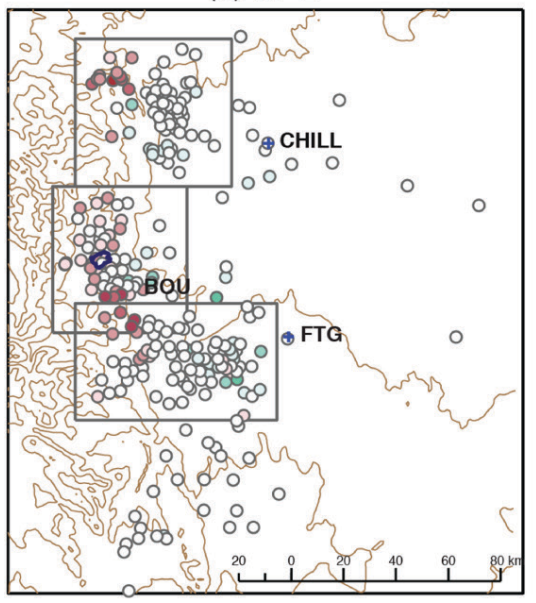

(b) KFTG Tropical Z-R

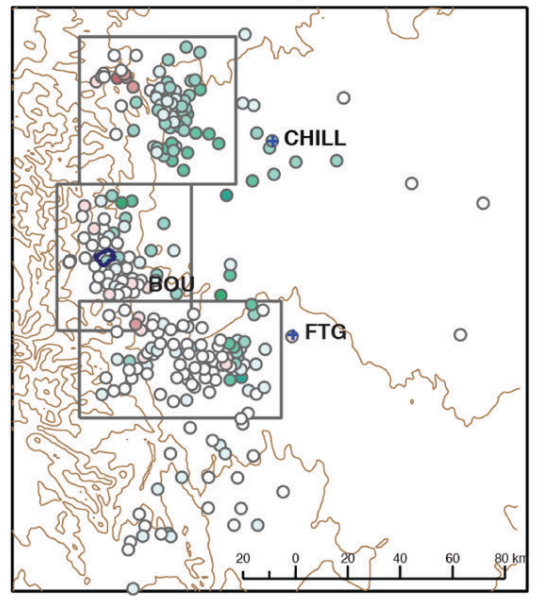

(e) Stage IV

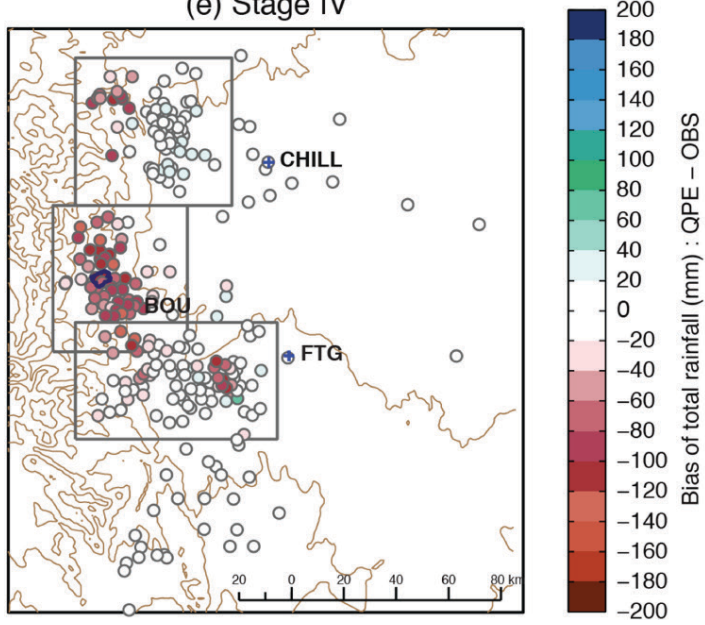

(c) KFTG Dual-pol

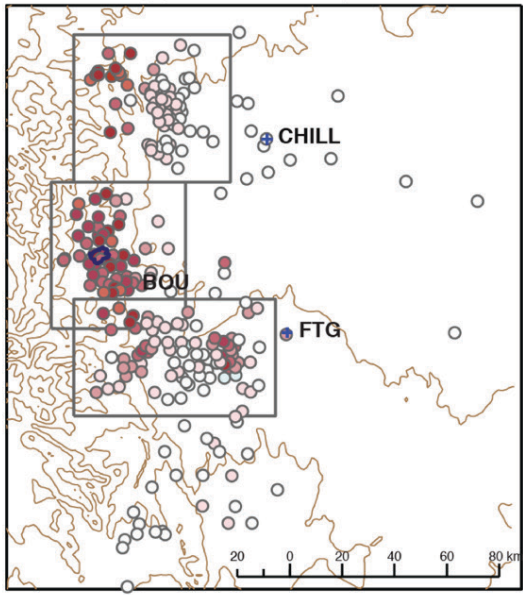

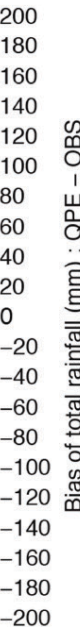

FIG. I2. Point station bias estimates of 2-day (0000 UTC II Sep-0000 UTC I3 Sep) estimated rainfall from (a) KFTG default Z-R, (b) KFTG tropical Z-R, (c) KFTG dual-pol-based estimates, (d) MPE, and (e) stage IV. The bias is computed from QPE minus observation.

capable of producing realistic rainfall from this event and underestimated regional rainfall amounts by greater than $50 \%$. Because of the dominance of small size raindrops that produce little change in the dual-polarization radar parameters as shown in the "Cloud and hydrometeor processes" section, dual-polarization precipitation estimates, while usually better than the default NEXRAD $Z-R$ estimate, also did not verify well with regional qualitycontrolled gauge data. Effectively, dual-polarization estimators did not have enough differential signal to properly constrain the rainfall estimates, and as such algorithms like the Cifelli et al. (2011) retrieval methodology used in CHILL or the Ryzhkov et al. (2005) used in the NWS dual-polarization retrieval still suffered some apparent deficiencies. Conversely, estimating rainfall with the aggressive, tropical $Z-R$ relationship provided much greater real-time precipitation estimates where biases were positive and on the order of $10 \%-20 \%$.

There was a surprising difference between the MPE and stage IV gauge-corrected products where the MPE product clearly exhibited superior performance. This is surprising because the products are derived from the same operational radar product and are adjusted with much, though not all, of the same gauge data. The difference between MPE and stage IV is attributed to merging additional rain-gauge data and performing additional manual quality control after more gauge data become available in the MPE product. It is evident that operational QPE products exhibited a wide range in their estimates that produced additional uncertainty for hydrometeorological forecasters and subsequently for decision makers who needed to respond and plan for critical operations during the event. The QPE analysis 


\begin{tabular}{|c|c|c|c|c|c|c|}
\hline \multicolumn{7}{|l|}{ Region I (78) } \\
\hline & Obs & Stage IV & MPE & NEXRAD default $Z-R$ & NEXRAD tropical Z-R & Dual-polarization NEXRAD \\
\hline 2-day total $(\mathrm{mm})$ & 76.0 & 87.6 & 76.2 & 30.5 & 121.1 & 50.9 \\
\hline Bias (mm) & & 8.0 & -1.5 & -46.1 & 38.3 & -26.1 \\
\hline \multicolumn{7}{|l|}{ Region 2 (69) } \\
\hline & Obs & Stage IV & MPE & NEXRAD default $Z-R$ & NEXRAD tropical Z-R & Dual-polarization NEXRAD \\
\hline 2-day total $(\mathrm{mm})$ & 200.0 & 120.7 & 162.9 & 46.7 & 201.4 & 103.9 \\
\hline Bias (mm) & & -74.3 & -22.0 & -140.8 & 8.5 & -81.3 \\
\hline \multicolumn{7}{|l|}{ Region 3 (87) } \\
\hline & Obs & Stage IV & MPE & NEXRAD default $Z-R$ & NEXRAD tropical $Z-R$ & Dual-polarization NEXRAD \\
\hline 2-day total $(\mathrm{mm})$ & 74.0 & 65.2 & 71.2 & 17.1 & 94.3 & 42.5 \\
\hline Bias $(\mathrm{mm})$ & & -13.2 & -1.2 & -57.8 & 14.4 & -36.1 \\
\hline
\end{tabular}

provided here and the hydrometeor descriptions presented earlier suggests there is some potential for additional value to be added to operational radar QPE products through the incorporation of additional information sources such as real-time direct measurement of precipitation amounts through gauges and, potentially, drop-size distributions, real-time $Z-R$ relationship analyses from disdrometers, and information on microphysical processes from vertically profiling radars.

\section{ANALYSIS OF QUANTITATIVE PRECIPITA- TION FORECASTS AND STREAMFLOW} FORECASTS. Following the floods, the performance of operational precipitation and flood forecast products became a matter of considerable interest. In-depth information on weather forecast model skill for this event is available in NWS (2014), Schwarz (2014), Hamill (2014), and Lavers and Villarini (2013). Thus, only a brief analysis of precipitation and flood forecasts is provided here.

We present a sequence of $12-60$-h forecasts centered on the heaviest rainfall period (0000 UTC 11 September-1300 UTC 12 September), highlighting lead times relevant to the issuance of NWS watches and warnings. Figure 13 shows six predictions from operational numerical weather prediction (NWP) models (Figs. 13a-f), from the NCEP Weather Prediction Center (WPC) forecasters (Fig. 13g), and a verifying analysis (Fig. 13h). These forecast products are generally available in real time to inform the official NWS Weather Forecast Office (WFO) forecasts and consequent guidance. The QPFs show heavy precipitation was forecasted for the 60 -h period beginning
0000 UTC 11 September, with all models indicating rainfall maxima exceeding $50 \mathrm{~mm}$ (2 in.) over this time period. (For reference, the entire monthly average precipitation for September at Boulder is approximately $40 \mathrm{~mm}$.) Most models placed a relative QPF maximum in or near the northern Front Range, though none successfully captured the large observed magnitude or the extent of the elongated axis of heavy rainfall stretching from the Colorado-Wyoming border southward to central Colorado (Fig. 13h). The 60-h synthesis forecast generated by human forecasters at the WPC in Fig. 13g improved upon all of the numerical model forecasts in its placement, extent, and intensity of the northern Front Range QPF maximum but still underpredicted the observed totals from NCEP stage IV by more than $50 \%$. The two ensemblemean forecasts (Figs. 13d,f) and the WPC forecast (a subjective ensemble consensus) had slightly reduced intensities and spatial granularity relative to the other forecasts but focused the precipitation in a reasonably consistent pattern across most of the northern Front Range. The notable performance of the NWS shortrange ensemble forecast (SREF) product evident in Fig. 13d was also noted in the NWS service assessment (NWS 2014).

While the placement of precipitation maxima in the northern Front Range by most models likely offered valuable forecast guidance, spurious QPF maxima [e.g., the Global Forecast System (GFS) large QPF maximum in eastern Kansas; Fig. 13a] could undercut the perception of model performance by way of false alarm errors. The similarity of QPF from the higher-resolution North American Mesoscale Forecast System (NAM) 4-km nest (Fig. 13c) to its 


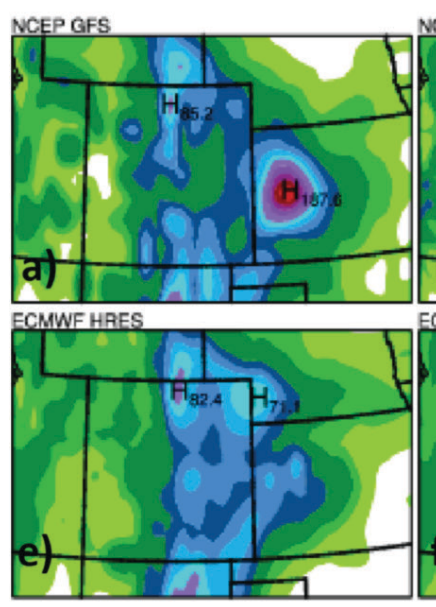

NCEP NAM

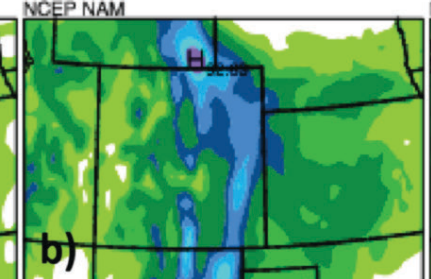

ECMWF EPS mean

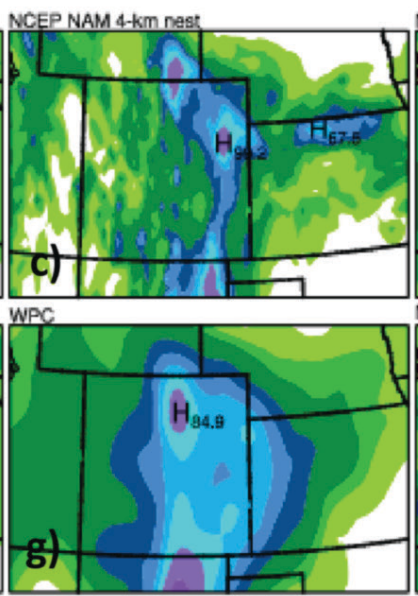

NCEP SREF mean

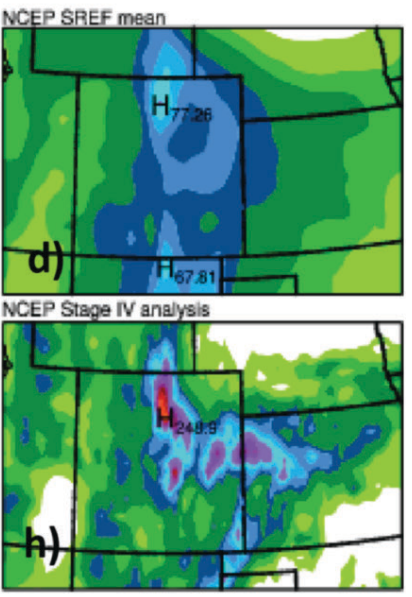

12-60-h precipitation (mm)

FIG. I3. Predicted and analyzed accumulated precipitation in the 48-h period initialized from 0000 UTC I I Sep from the (a) NCEP GFS, (b) NCEP NAM ( 2 km), (c) NCEP NAM (4 km), (d) NCEP SREF mean, (e) European Centre for Medium-Range Weather Forecasts (ECMWF) HRES model, (f) ECMWF Ensemble Prediction System (EPS) mean, (g) NOAA WPC (human forecast), and (h) NCEP stage IV merged radar-gauge analysis. All forecasts and the analysis were regridded to a common $0.2^{\circ}$ latitude-longitude domain.

lower-resolution parent (NAM in Fig. 13b) suggests that increased model resolution did not substantially improve that model's forecast accuracy for the event.

In summary, operational rainfall forecasts did predict a significant precipitation event focused in the northern Front Range of Colorado, although predicted rainfall totals were far lower than what was observed. In the 1-2 days preceding the heaviest rainfall, the forecast guidance likely offered value to local WFO forecasters, and this guidance is noted in NWS (2014).

The NWS service assessment (NWS 2014) also suggests that there were shortcomings in how QPF and QPE information is translated into flood guidance information and products. Two kinds of quantitative flood forecast information are typically available during events like the Colorado Front Range flood. The first is called flash flood guidance (FFG), which is a time-varying, rainfall accumulation threshold above which flash flooding is likely (Clark et al. 2014). Using a combination of a soil moisture accounting model and historical rainfall and streamflow data, FFG numbers track patterns of antecedent accumulated rainfall to account for the remaining amount of water storage the land surface can provide before flooding ensues. As a result of the increasing soil saturation levels described above, FFG values from the Missouri Basin River Forecast Center (MBRFC) decreased from over $76.2 \mathrm{~mm}$
(3 in.) on 9 September to under $6.4 \mathrm{~mm}$ (0.25 in.) by 13 September for appreciable parts of Boulder, Larimer, and Jefferson Counties in the Front Range region (Fig. A4). The mountainous regions of the Boulder Creek, Lefthand Creek, St. Vrain, and Little and Big Thompson watersheds saw the largest changes in FFG values during the event. These dramatic reductions in FFG values during the event aided in the dissemination of over 70 flash flood warnings issued by the Denver/Boulder and Pueblo NWS Forecast Offices during the event (NWS 2014).

The second type of quantitative flood forecast information is point forecasts of river stage and streamflow at predetermined gauging stations. From the city of Denver north to the Wyoming border, there were approximately 19 stations at which the MBRFC produced streamflow forecasts, mostly on the plains. The performance of streamflow forecasts was strongly dependent on the size and response time of the contributing catchment. In general, forecasts in smaller, fast-responding watersheds gave the least lead time in predicting flood stage and showed the largest relative underpredictions. In contrast, forecasts for larger, slow-responding drainage areas were better able to predict the magnitude of river rises, despite also generally underestimating the crest arrival time. Figure 14 illustrates these tendencies by showing sequences of river stage forecasts and observations during the event for fast (North Fork of the Big Thompson 
River above Drake), medium (South Platte River at Weldona), and slow (South Platte River at Julesburg, near the Nebraska state line) response time watersheds (with drainage areas of $305,13,190$, and 22,821 $\mathrm{mi}^{2}$, respectively). Forecasting floods in small watersheds is particularly challenging because of uncertainties in both the location and intensity of forecasted rainfall, a problem that is relatively dampened over larger forecast areas. Finally, for the larger basins analyzed, forecasts of river recession characteristics were more accurate than predictions of the rising limb of the flood hydrograph. Additional information on the
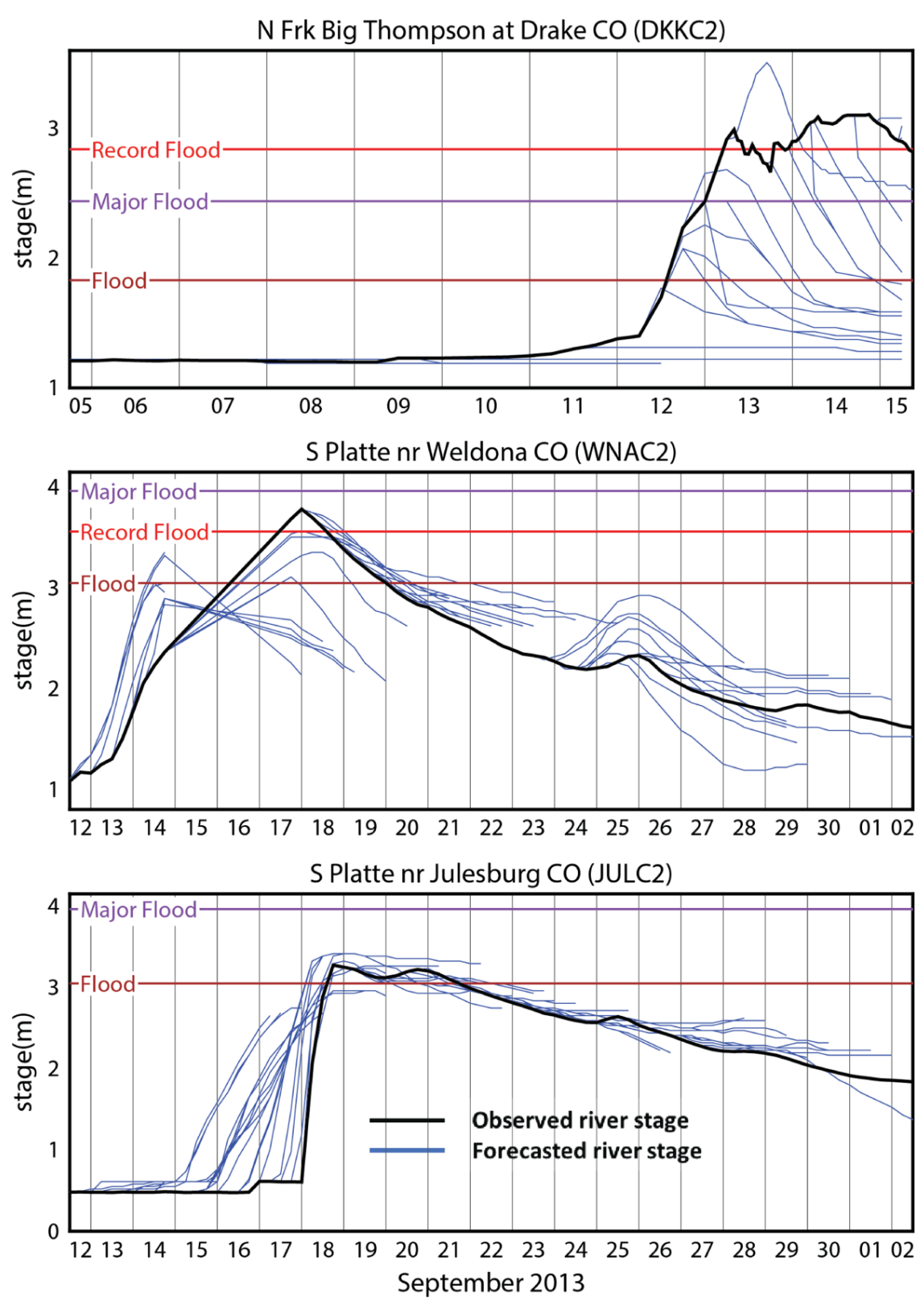

FIG. 14. NWS river stage forecasts (blue) and observations (black) for river locations with different relative response times: (top) fast, (middle) medium, and (bottom) slow. verification of flood and flash flood warnings is available in NWS (2014).

CONCLUSIONS. The historical record of floods in the Colorado Front Range is replete with events generated by large summer thunderstorms or sustained periods of springtime rains on top of rivers swollen with snowmelt. The events of September 2013 add another chapter to this history for which the only comparable event was reported to have occurred in 1938. In a time of year when summer thunderstorms occur with less than half the frequency of June, July, or August and cool-season upslope storms are not yet very common, many streams are typically beginning to run dry before the onset of winter. Most of the region's inhabitants are used to enjoying shortening, warm, dry days and cool, clear nights. September 2013, however, will hold different memories, when record heat abruptly turned to days of relentless rain that, in turn, brought water and hillsides down, rivers out of their banks, widespread destruction, and tragic loss.

The synergy of the meteorological conditions witnessed during these events provides an opportunity to learn how extreme hydrometeorological events evolve as well as a critical chance to evaluate, improve, and harden flood prediction and protection infrastructure. Of the over $400 \mathrm{~mm}$ of rainfall that fell in some locations, much of that rainfall was not well estimated using typical radar $Z-R$ relationships or current polarimetric rainfallrate retrieval algorithms. Low cloud bases with a $2.5-\mathrm{km}$-deep warm-cloud 
zone, terrain blockage in higher mountain areas, low evaporation rates, and a dominance of small raindrops at the surface, which was unusual for this particular region and season, resulted in nearly all operational QPE products significantly underestimating rainfall amounts. Numerical weather prediction models showed some skill in capturing the large-scale moisture advection features that would bring record atmospheric moisture levels and heavy rainfall to the region, but most of the operational models significantly underestimated total rainfall amounts and often possessed significant errors in predicting where heavy rainfall would occur. These findings on QPF performance are consistent with other recent reports including the NWS service assessment on the September flood event. Owing partly to these deficiencies, advanced flood preparedness information was not available until the event actually began to unfold, particularly in headwater regions along the mountains. Until as little as 12 hours before the main flooding period, no flood or flash flood watch was issued in the critically impacted areas of Boulder and Larimer Counties on 11 September, though we note that a flash flood watch was issued for regions farther south in Colorado. Lacking confident guidance in QPFs and QPEs, and associated streamflow forecasts, forecasters, emergency management personnel, and researchers, the media and public turned to local networks of surface observations for information as the event unfolded. Those networks provided invaluable information on where the heaviest rainfall and flooding was taking place until, in some cases, those instruments were destroyed during the event. It cannot be overemphasized how much more dangerous this event would likely have been to the population without the information from these instrument networks feeding into local forecast offices, emergency response agencies, the media, and the public alike, particularly in remote mountain locations.

This paper documents many aspects of the September flooding event and points the way to new observations and tools that potentially have significant value in the future. While operational radar products had difficulty in estimating rainfall during the event, research networks of surface disdrometers and vertically pointing radars were able to measure, in real time, important raindrop-size distribution information and the vertical profile of reflectivity information that may provide critical guidance for improving real-time rain-rate estimates from radars. Systems, such as VDRAS that can rapidly (e.g., approximately every $10 \mathrm{~min}$ ) assimilate Doppler radar reflectivity and radial velocity data offer an opportunity to provide frequent, high-resolution (HRES) updates on evolving mesoscale winds, convergence, and updraft regions. Such capabilities should lead to improved nowcasts and forecasts of precipitation. Other advanced data assimilation systems, such as three- and four-dimensional variational systems or the gridpoint statistical interpolation (DTC 2014) system, with radar data assimilation also have the potential to yield improved forecasts of precipitation. New research weather forecast models such as the

NOAA/NESDIS SST Anomaly (degrees C), $9 / 9 / 2013$

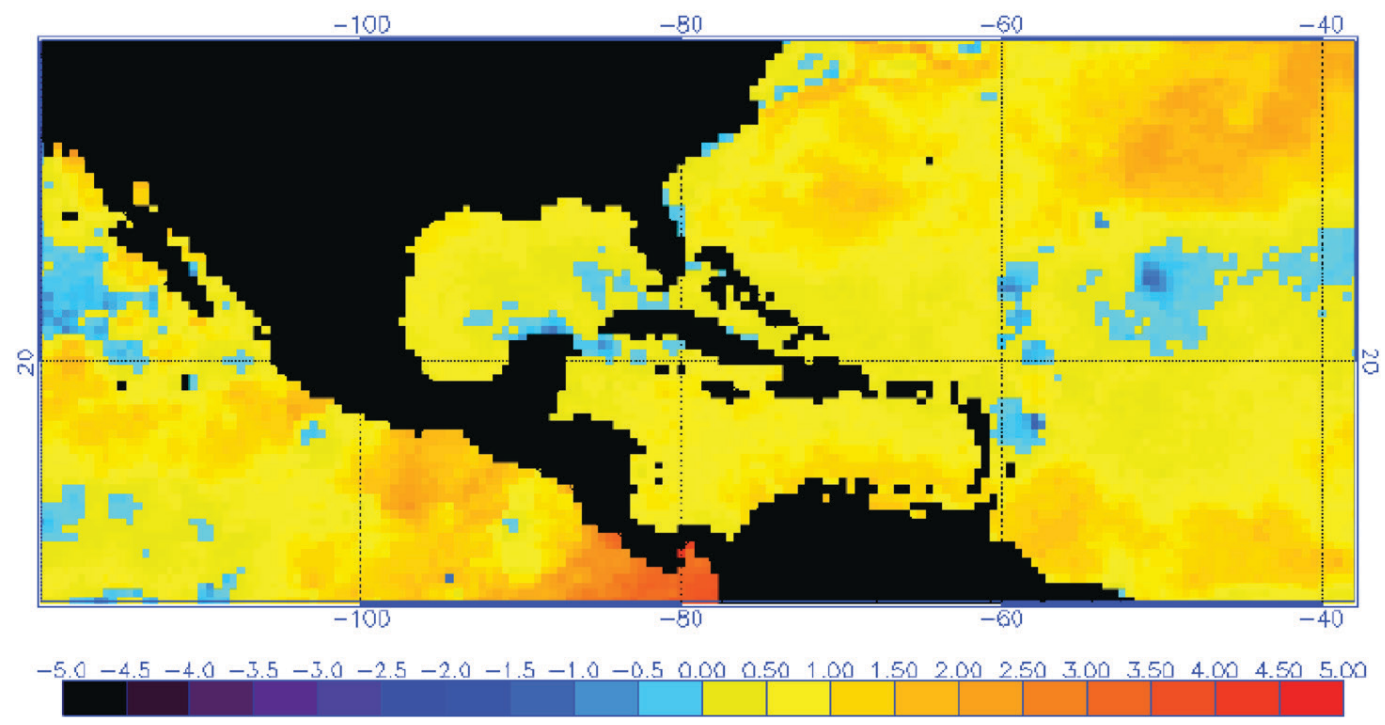

Fig. AI. Sea surface temperature anomaly $\left({ }^{\circ} \mathrm{C}\right)$ for 9 Sep 2013. (Source: NOAA/NESDIS.) 
a) KFTG radar: 12 Sept 0200-0600 UTC
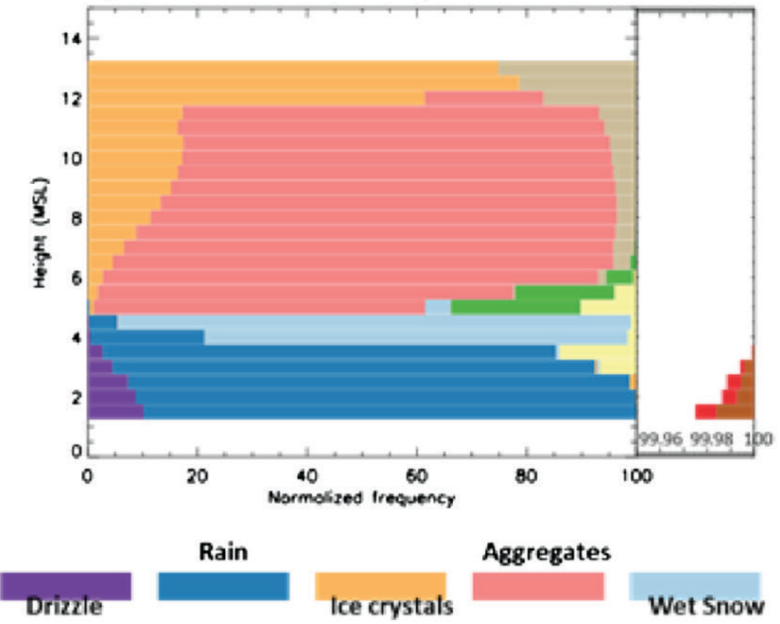

b) CHILL radar: 12 Sept 2100-2400 UTC

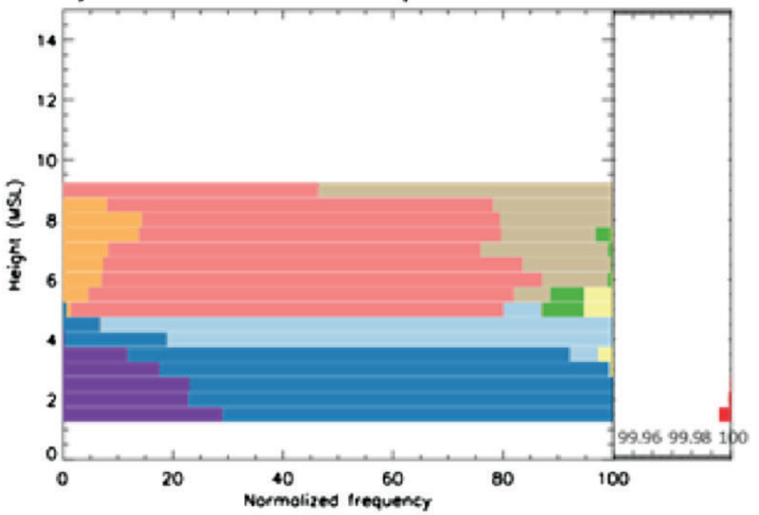

$\begin{array}{ccc}\text { Vertical ice } & \text { High-density graupel Big drops/Melting hail } \\ \text { Low-density graupel } & \text { Hail }\end{array}$

FIG. A2. Normalized frequency of occurrence of hydrometeor classification by height (km) for the time periods (a) 0200-0500 UTC using KFTG data and (b) 2100-2400 UTC using CSU-CHILL data. Big drops/melting hail and hail have frequencies smaller than $0.05 \%$ and are therefore shown in the subset axes to the right of each figure. [Although the same algorithm was used during both time periods, the polarized NEXRAD KFTG radar was used during the early period (0200-0500 UTC) because of the lack of corresponding CSU-CHILL data. The two radars have different scanning strategies, with the CSU-CHILL radar performing fewer high-elevation angles to capture the upper levels. The plots are gridded to the same horizontal domain centered on CHILL and facing west, with a $0.5-\mathrm{km}$ horizontal and vertical resolution.]

NOAA High-Resolution Rapid Refresh (HRRR) model may offer new opportunities to rapidly assimilate such mesoscale information and improve short-term QPFs. Similarly, new generations of spatially continuous hydrological models that utilize new hydrologic data assimilation methodologies, as opposed to simpler point forecast models, should be able to provide additional information on the location and timing of floods in small headwater regions if more accurate rainfall estimates and forecasts can be provided. In addition to the challenges of rebuilding the communities destroyed by the floods, the challenge of improving regional observational and prediction systems is also set. As improved awareness of this poorly understood kind of flood risk settles in, so too must a renewed commitment to preparing ourselves for its eventual return.

ACKNOWLEDGMENTS. We wish to extend our thanks to the following for their assistance in this article: The USGS, Colorado Division of Water Resources and Denver Urban Drainage and Flood Control District for streamflow and precipitation data; the U.S. National Weather Service, Northern Colorado Water Conservancy, Natural Resources Conservation Service Colorado Agricultural Meteorological network, and the CoCoRAHS network for precipitation data and other meteorological information; the Colorado Water Conservation Board for sharing peak flow information; Julie Meyer and Kevin Low of the
NWS Missouri Basin River Forecast Center in Pleasant Hill, Missouri; Matt Bunkers for sharing the precipitable water information; and Adam Smith of the National Climatic Data Center for the estimated damage costs resulting from the event. NARR analyses, radiosonde observations, and forecast model output were obtained from the National Climatic Data Center. Thanks to David Novak and Mark Klein for providing the archived WPC forecasts. We also extend our thanks to three anonymous reviewers and BAMS editor Jeff Waldstreicher for their constructive critiques of our original manuscript. The artful editorial contributions of Karen Griggs and Bobbetta Gochis are deeply appreciated. The views, opinions, and findings in this report are those of the authors and should not be construed as an official NSF, NOAA, or U.S. government position, policy, or decision. Schumacher was partially supported by National Science Foundation Grant AGS-1157425. This work was supported in part by the U.S. National Science Foundation through its support of NCAR.

APPENDIX: ADDITIONAL FIGURES. Figures A1-A4 support the diagnostic analysis described in the body text. Specifically, Figs. A1-A4 show sea surface temperature anomalies, hydrometeor particle type estimates, in situ soil moisture measurements, and operational flash flood guidance products, respectively. 


\section{Volumetric Soil Moisture at the U. of Colorado Mountain Research Laboratory C-1 Site}

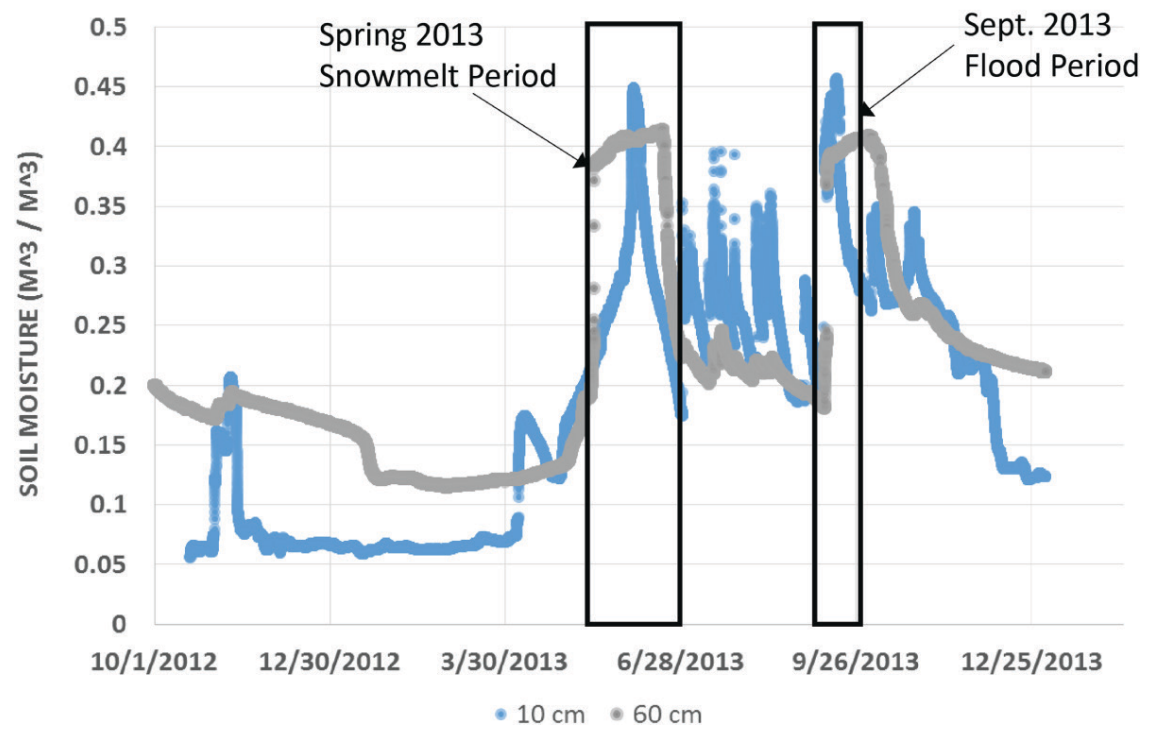

Fig. A3. Soil moisture values at $10-$ and $60-\mathrm{cm}$ depth from the University of Colorado Mountain Research Station approximately $30 \mathrm{~km}$ west of Boulder at $3,300 \mathrm{~m}$ MSL elevation. The period from I Oct 2012 to I Jan 2014 is shown to illustrate that values observed during the Sep 2013 floods were similar to saturated soil moisture conditions observed during peak snowmelt periods.

6h FFG issued 00z, 09 Sep 2013.

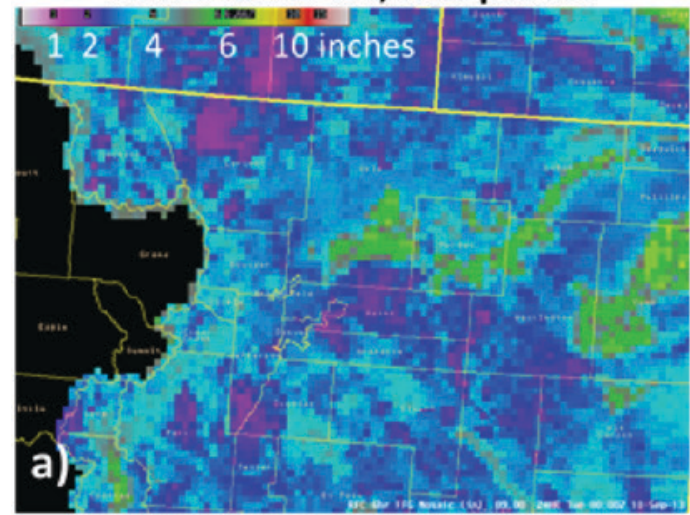

6h FFG issued 12z, 12 Sep 2013.

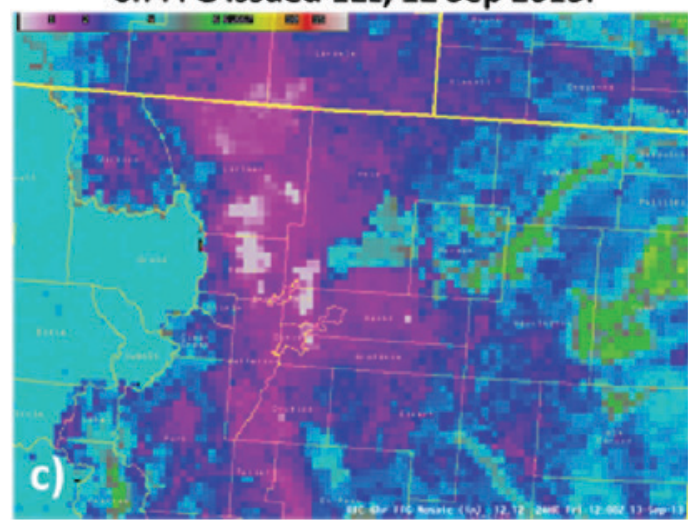

6h FFG issued 122, 11 Sep 2013.

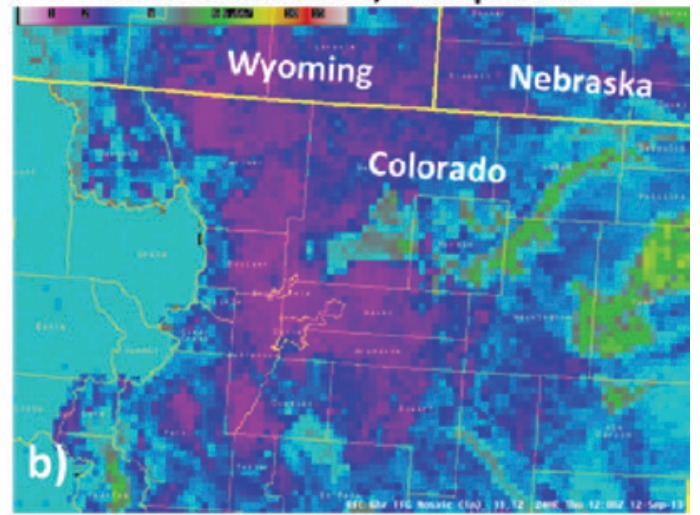

6h FFG issued 00z, 13 Sep 2013.

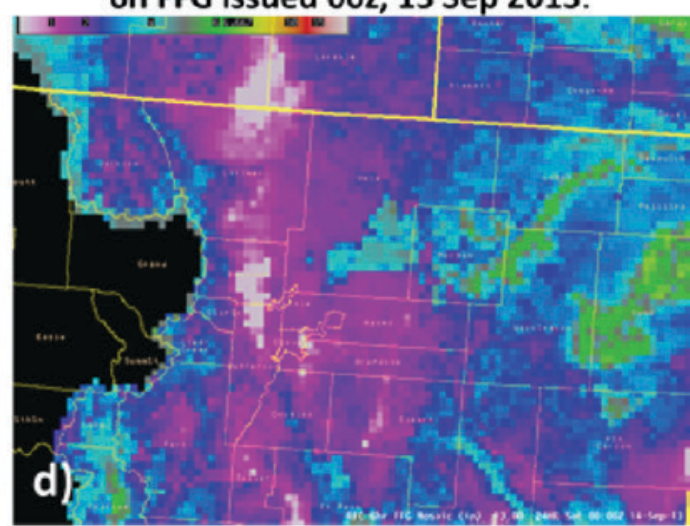

FIG. A4. FFG from upper MBRFC for four different forecast times from 9 to 13 Sep 2013. Color shading indicates the threshold amount of rainfall (in.) required to generate significant flooding. 


\section{REFERENCES}

BASIN, cited 2014: Flood of 1938-Eldorado Springs. Boulder Area Sustainability Information Network. [Available online at http://bcn.boulder.co.us/basin /history/1938flood.html.]

Bringi, V. N., and V. Chandrasekar, 2001: Polarimetric Doppler Weather Radar. Cambridge University Press, $636 \mathrm{pp}$.

-, - J. Hubbert, E. Gorgucci, W. L. Randeu, and M. Schoenhuber, 2003: Raindrop size distribution in different climatic regimes from disdrometer and dual-polarized radar analysis. J. Atmos. Sci., 60, 354-365, doi:10.1175/1520-0469(2003)060<0354:RS DIDC $>2.0 . C O ; 2$.

Caracena, F., R. A. Maddox, L. R. Hoxit, and C. F. Chappell, 1979: Mesoanalysis of the Big Thompson storm. Mon. Wea. Rev., 107, 1-17, doi:10.1175/1520 -0493(1979)107<0001:MOTBTS>2.0.CO;2.

Cifelli, R., V. Chandrasekar, S. Lim, P. C. Kennedy, Y. Wang, and S. A. Rutledge, 2011: A new dual-polarization radar rainfall algorithm: Application in Colorado precipitation events. J. Atmos. Oceanic Technol., 28, 352-364, doi:10.1175/2010JTECHA1488.1.

Clark, R. A., J. J. Gourley, Z. L. Fleming, Y. Hong, and E. Clark, 2014: CONUS-wide evaluation of National Weather Service flash flood guidance products. Wea. Forecasting, 29, 377-392, doi:10.1175/WAF -D-12-00124.1.

Coe, J. A., J. W. Kean, J. W. Godt, R. L. Baum, E. S. Jones, D. J. Gochis, and G. S. Anderson, 2014: New insights into debris-flow hazards from an extraordinary event in the Colorado Front Range. GSA Today, 24, 4-10, doi:10.1130/GSATG214A.1.

Crook, N. A., T. L. Clark, and M. W. Moncrieff, 1990: The Denver cyclone. Part I: Generation in low Froude number flow. J. Atmos. Sci., 47, 2725-2742, doi:10.1175/1520 -0469(1990)047<2725:TDCPIG>2.0.CO;2.

DTC, 2014a: Community gridpoint statistical interpolation system. Developmental Testbed Center. [Available online at www.dtcenter.org/com-GSI/users/.]

_ , 2014b: Model Evaluation Tools verification package. DTC. [Available online at www.dtcenter.org /met/users/.]

Hamill, T. M., 2014: Performance of operational model precipitation forecast guidance during the 2013 Colorado Front-Range floods. Mon. Wea. Rev., 142, 2609-2618, doi:10.1175/MWR-D-14-00007.1.

Hart, R. E., and R. H. Grumm, 2001: Using normalized climatological anomalies to rank synoptic-scale events objectively. Mon. Wea. Rev., 129, 2426-2442, doi:10.1175/1520-0493(2001)129<2426:UNCATR $>2.0 . \mathrm{CO} ; 2$.
Houck, K., 2014: CDOT/CWCB hydrology investigation phase one-2013 flood peak determinations. State of Colorado Official Memo., 8 pp.

Kennedy, P. C., S. A. Rutledge, W. A. Petersen, and V. N. Bringi, 2001: Polarimetric radar observations of hail formation. J. Appl. Meteor., 40, 1347-1366, doi:10.1175/1520-0450(2001)040<1347:PROOHF $>2.0 . \mathrm{CO} ; 2$.

Kitzmiller, D., D. Miller, R. Fulton, and F. Ding, 2013: Radar and multisensor precipitation estimation techniques in National Weather Service hydrologic operations. J. Hydrol. Eng., 18, 133-142, doi:10.1061 /(ASCE)HE.1943-5584.0000523.

Lavers, D. A., and G. Villarini, 2013: Were global numerical weather prediction systems capable of forecasting the extreme Colorado rainfall of 9-16 September 2013? Geophys. Res. Lett., 40, 6405-6410, doi:10.1002/2013GL058282.

Lin, Y., and K. E. Mitchell, 2005: The NCEP stage II/ IV hourly precipitation analyses: Development and applications. Preprints, 19th Conf. on Hydrology, San Diego, CA, Amer. Meteor. Soc., 1.2. [Available online at http://ams.confex.com/ams/pdfpapers/83847 .pdf.]

Maddox, R. A., 1980: Mesoscale convective complexes. Bull. Amer. Meteor. Soc., 61, 1374-1387, doi:10.1175/1520-0477(1980)061<1374:MCC >2.0 .CO;2.

- L. R. Hoxit, C. F. Chappell, and F. Caracena, 1978: Comparison of meteorological aspects of the Big Thompson and Rapid City flash floods. Mon. Wea. Rev., 106, 375-389, doi:10.1175/1520 -0493(1978)106<0375:COMAOT>2.0.CO;2.

Matrosov, S. Y., R. Cifelli, P. C. Kennedy, S. W. Nesbitt, S. A. Rutledge, V. N. Bringi, and B. E. Martner, 2006: A comparative study of rainfall retrievals based on specific differential shifts at X- and S-band radar frequencies. J. Atmos. Oceanic Technol., 23, 952-963, doi:10.1175/JTECH1887.1.

Mesinger, F., and Coauthors, 2006: North American Regional Reanalysis. Bull. Amer. Meteor. Soc., 87, 343-360, doi:10.1175/BAMS-87-3-343.

Michaud, J. D., K. K. Hirschboeck, and M. Winchell, 2001: Regional variations in small-basin floods in the United States. Water Resour. Res., 37, 1405-1416, doi:10.1029/2000WR900283.

Mishchenko, M. I., L. D. Travis, and D. W. Mackowski, 1996: T-matrix computations of light scattering by nonspherical particles: A review. J. Quant. Spectrosc. Radiat. Transfer, 55, 535-575, doi:10.1016/0022 -4073(96)00002-7.

Moody, J. A., R. A. Shakesby, P. R. Robichaud, S. H. Cannon, and D. A. Martin, 2013: Current research 
issues related to post-wildfire runoff and erosion processes. Earth Sci. Rev., 122, 10-37, doi:10.1016/j .earscirev.2013.03.004.

NWS, 2013a: Exceedance probability analysis for the Colorado flood event, 9-16 September 2013. Hydrometeorological Design Studies Center Rep., 5 pp. [Available online at www.nws.noaa.gov/oh /hdsc/aep_storm_analysis/8_Colorado_2013.pdf.]

— , 2013b: The Denver CO climate summary for the year of 2013. National Weather Service Boulder Climate Rep. [Available online at www.crh.noaa.gov/bou/include/showProduct. php?product $=$ denclm_2013.txt.]

_ 2014: The record Front Range and eastern Colorado floods of September 11-17, 2013. U.S. Department of Commerce/National Oceanic and Atmospheric Administration Service Assessment, 74 pp. [Available online at www.nws.noaa.gov/om/assessments /pdfs/14colorado_floods.pdf.]

Petersen, W. A., and Coauthors, 1999: Mesoscale and radar observations of the Fort Collins flash flood of 28 July 1997. Bull. Amer. Meteor. Soc., 80, 191-216, doi:10.1175/1520-0477(1999)080<0191:MAROOT $>2.0 . \mathrm{CO} ; 2$.

Ryzhkov, A. V., S. E. Giangrande, and T. J. Schuur, 2005: Rainfall estimation with a polarimetric prototype of WSR-88D. J. Appl. Meteor., 44, 502-515, doi:10.1175 /JAM2213.1.

Schwarz, C. S., 2014: Reproducing the September 2013 record-breaking rainfall over the Colorado Front Range with high-resolution WRF model forecasts. Wea. Forecasting, 29, 393-402, doi:10.1175/WAF -D-13-00136.1.
Stewart, K., 2013: Information services and flood warning notes. Flood Hazard News, Vol. 43, Urban Drainage and Flood Control District, Denver, CO, 14-25. [Available online at www.udfcd.org/downloads/pdf /fhn/fhn2013/fhn2013.pdf.]

Sun, J., and N. A. Crook, 1997: Dynamical and microphysical retrieval from Doppler radar observations using a cloud model and its adjoint. Part I: Model development and simulated data experiments. $J$. Atmos. Sci., 54, 1642-1661, doi:10.1175/1520 -0469(1997)054<1642:DAMRFD>2.0.CO;2.

Szoke, E. J., M. L. Weisman, J. M. Brown, F. Caracena, and T. W. Schlatter, 1984: A subsynoptic analysis of the Denver tornado of 3 June 1981. Mon. Wea. Rev., 112, 790-808, doi:10.1175/1520-0493(1984)112<0790:AS AOTD>2.0.CO;2.

Vivekanandan, J., W. M. Adams, and V. N. Bringi, 1991: Rigorous approach to polarimetric radar modeling of hydrometeor distributions. J. Appl. Meteor., 30, 10531063, doi:10.1175/1520-0450(1991)030<1053:RATPR $\mathrm{M}>2.0 . \mathrm{CO} ; 2$

Waterman, P. C., 1965: Matrix formulation of electromagnetic scattering. Proc. IEEE, 53, 805-812, doi:10.1109/PROC.1965.4058.

Wilczak, J. M., and T. W. Christian, 1990: Case study of an orographically induced mesoscale vortex (Denver cyclone). Mon. Wea. Rev., 118, 1082-1102, doi:10.1175/1520-0493(1990)118<1082:CSOAOI $>2.0 . \mathrm{CO} ; 2$.

Yochum, S. E., and D. S. Moore, 2013: Colorado Front Range flood of 2013: Peak flow estimates at selected mountain stream locations. USDA Natural Resources Conservation Service Tech. Rep., 44 pp. 


\section{Find out from the authoritative source}

웅

[ What's a dust devil? ]

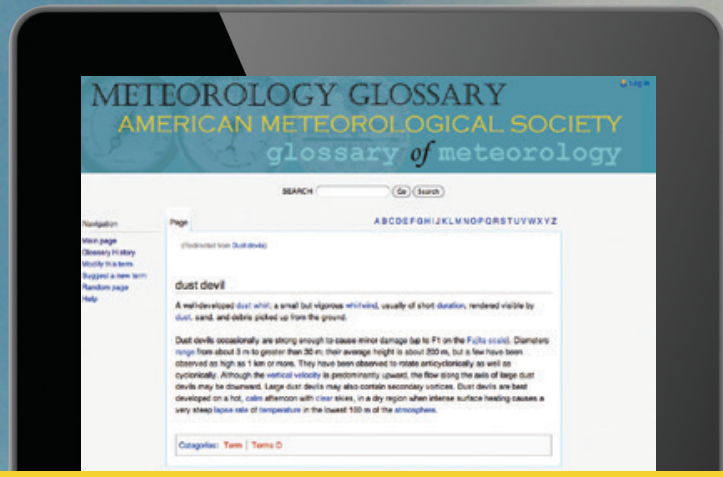

THE AMERICAN METEOROLOEICAL SOCIETV

\section{Online Glossary of Meteorology}

With over 12,000 meteorological terms, you'll be able to look up definitions online any time, any place, anywhere.

http://glossary.ametsoc.org/wiki

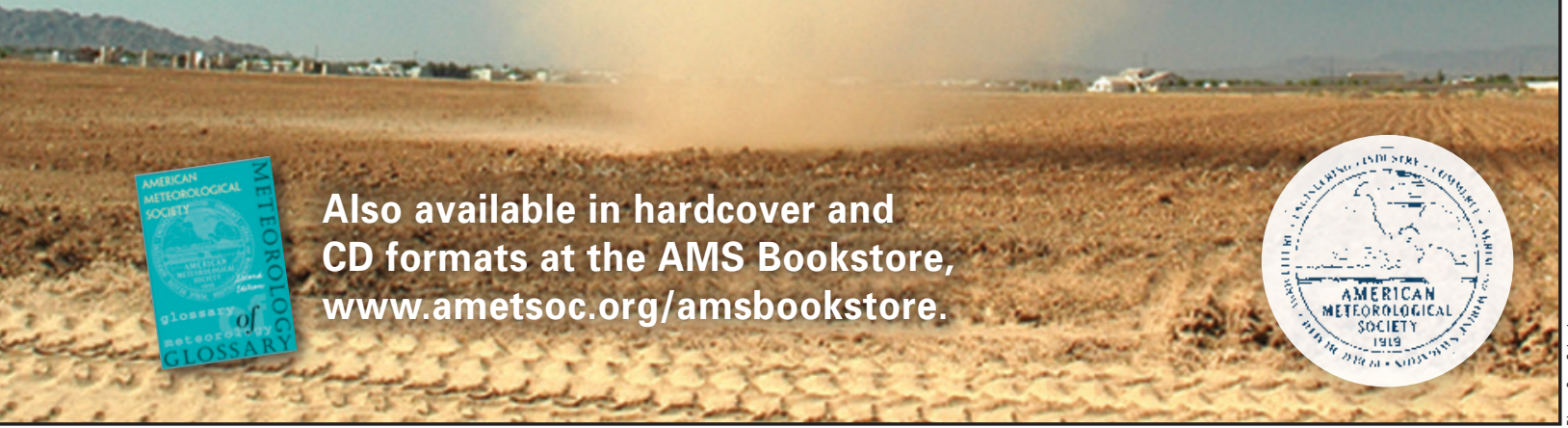

